INRA Prod. Anim.,

2014, 27 (4), 255-268

\title{
Phénotypage et génotypage à grande échelle de la composition fine des laits dans les filières bovine, ovine et caprine
}

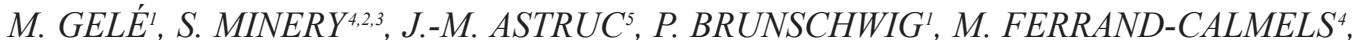 \\ G. LAGRIFFOUL ${ }^{5}$, H. LARROQUE ${ }^{6,7,8,9}$, J. LEGARTO ${ }^{5}$, O. LERAY ${ }^{10}$, P. MARTIN ${ }^{2,3}$, G. MIRANDA ${ }^{2,3}$, \\ I. PALHIERE ${ }^{6,7,8,9}$, P. TROSSAT ${ }^{10}$, M. BROCHARD ${ }^{4,2,3}$ \\ ${ }^{1}$ Institut de l'Élevage, CS 70510, F-49105 Angers, France \\ 2 INRA, UMR1313 GABI, F-78352 Jouy-en-Josas, France \\ 3 AgroParisTech, UMR1313 GABI, F-75231 Paris, France \\ 4 Institut de l'Élevage, 149 rue de Bercy, F-75595 Paris, France \\ ${ }^{5}$ Institut de l'Élevage, BP 42118, F-31321 Castanet-Tolosan, France \\ ${ }^{6}$ INRA, UMR1388 GenPhySE, F-31326 Castanet-Tolosan, France \\ 7 Université de Toulouse INPT ENSAT, UMR1388 GenPhySE, F-31326 Castanet-Tolosan, France \\ ${ }^{8}$ Université de Toulouse INPT ENVT, UMR1388 GenPhySE, F-31076 Toulouse, France \\ ${ }^{9}$ Université de Toulouse INPT, Ecole d'Ingénieurs de Purpan, UMRI388 GenPhySE, F-31076 Toulouse, France \\ 10 Actalia Cecalait, F-39800 Poligny, France \\ Courriel : marine.gele@idele.fr
}

Bien que le lait constitue l'élément pivot entre l'amont et l'aval des filières laitières, la caractérisation à grande échelle de sa qualité intrinsèque reste assez rudimentaire. Une connaissance précise de sa composition est un enjeu majeur pour les filières qui doivent s'adapter aux attentes évolutives de leurs différents maillons et en particulier de celles des consommateurs.

Aujourd'hui, la valorisation du lait est basée sur une grille de paiement du lait prenant en compte des aspects de sa composition chimique globale : les teneurs en matière grasse (Taux Butyreux, TB) et protéique (Taux Protéique, TP). Depuis quelques années, les attentes des consommateurs occidentaux évoluent. En plus d'une qualité sanitaire irréprochable, les aliments doivent présenter des qualités nutritionnelles reconnues. Bien que le lait bénéficie d'une image majoritairement favorable, il est de plus en plus remis en cause en raison des matières grasses qu'il contient, jugées trop riches en Acides Gras (AG) saturés et trans, et $\mathrm{du}$ potentiel allergène de certaines de ses protéines. Il est apparu stratégique pour les filières laitières françaises d'affiner les connaissances sur la composition des laits en étudiant en détail les $\mathrm{AG}$ et les protéines et d'élaborer des outils permettant aux éleveurs de la maîtriser. PhénoFinlait, programme d'ampleur nationale, avait pour enjeu l'étude de cette composition en $\mathrm{AG}$ et protéines, que nous appellerons " composition fine ", et de ses facteurs d'influence dans les populations bovine, caprine et ovine.

Le programme PhénoFinlait vise i) à estimer en routine la composition fine du lait en $A G$ et protéines de façon fiable, rapide et peu coûteuse, pour envisager ensuite une large collecte de données sur l'ensemble du territoire français, la méthode choisie étant la spectrométrie dans le Moyen InfraRouge (MIR) dont le potentiel de prédiction des teneurs détaillées en $A G$ a été démontré (Soyeurt et al 2006), ii) à constituer une base de données regroupant les phénotypes (composition en AG et en protéines), les génotypes des animaux et des informations sur les conduites d'élevage et l'alimentation des troupeaux et iii) à réaliser un état des lieux de la situation des trois espèces en France et identifier, pour chacune d'elles, les facteurs de variations de la composition fine du lait liés à l'environnement et à la génétique. La combinaison de trois éléments permet à PhénoFinlait de se distinguer des programmes analogues : le phénotypage à haut débit de la composition fine du lait grâce à l'utilisation de la spectrométrie MIR, l'étude combinée des déterminants génétiques et d'environnement de cette composition et enfin le travail simultané dans les trois espèces laitières. Parmi les programmes contemporains, la «Dutch Milk Initiative » (Visker et al 2006) qui étudie les gènes impliqués dans la variabilité des caractères de qualité du lait, en particulier la composition en AG et protéines du lait, était basée sur les méthodes physico-chimiques (Stoop et al 2008) avant d'utiliser la spectrométrie
MIR (Rutten et al 2009 et 2011). Ces travaux, comme ceux de Soyeurt et al (2006), concernent, en outre, uniquement l'espèce bovine (et seulement la race holstein pour les travaux néerlandais) et aucune donnée d'environnement n'a été collectée.

Cet article détaille la méthode de phénotypage à grande échelle des $A G$ et protéines grâce à des équations établies à partir de jeux d'échantillons spécifiques. Il décrit ensuite le dispositif de collecte mis en place dans PhénoFinlait et, enfin, dresse un état des lieux des données collectées, permettant d'actualiser les références sur la caractérisation des troupeaux, des femelles laitières, des régimes alimentaires et du profil des laits produits dans les trois filières laitières françaises.

\section{1 / Etablissement des équa- tions d'estimation de la com- position fine du lait}

Maîtriser la composition en AG et protéines du lait par des leviers alimentaires et/ou génétiques, nécessite un phénotypage à grande échelle de ces caractères. Une méthode de phénotypage utilisable en routine doit être pratique, rapide, peu onéreuse et fiable. Or, jusqu'alors la composition du lait en $\mathrm{AG}$ et 
protéines était mesurée par des méthodes chimiques : Chromatographie Phase Gazeuse (CPG) pour les AG et Chromatographie en Phase Liquide à Haute Performance (HPLC) pour les protéines. Ces méthodes sont peu adaptées au phénotypage à haut débit car longues à mettre en œuvre, partiellement automatisables et onéreuses.

La spectrométrie MIR est une méthode alternative utilisée en routine dans les laboratoires d'analyse du lait pour mesurer notamment les taux de Matières Grasse (MG) et Protéique (MP). Elle conditionne le paiement du lait à la qualité, le contrôle de performances, le conseil en élevage et par voie de conséquence la sélection génétique sur les caractères laitiers. Depuis quelques années, l'utilisation de la spectrométrie MIR est également proposée pour caractériser plus précisément les laits en estimant les teneurs en composants fins dont les AG (Soyeurt et al 2006).

\section{1 / Composition des matières grasse et protéique du lait de vache, chèvre et brebis}

La Matière Sèche (MS) du lait est constituée principalement de MG, MP, lactose et de minéraux. PhénoFinlait s'intéresse à la composition de la MG et de la MP du lait, présentes en quantités variables selon les espèces. Le lait de vache est plus riche en MG que le lait de chèvre : $39,6 \mathrm{~g} / \mathrm{kg}$ vs $36,7 \mathrm{~g} / \mathrm{kg}$ (Institut de l'Élevage et al 2013). En revanche, vache et chèvre produisent toutes deux en moyenne $32,4 \mathrm{~g} / \mathrm{kg}$ de MP (Institut de l'Élevage et al 2013). Le lait de brebis est plus concentré que les laits de chèvre et de vache tant en MG qu'en MP : respectivement $73,4 \mathrm{~g} / \mathrm{L}$ et $55,7 \mathrm{~g} / \mathrm{L}$ dans le Rayon de Roquefort (Rayon) et 71,8 g/L et $53,8 \mathrm{~g} / \mathrm{L}$ dans les Pyrénées-Atlantiques (P-A) (Confédération Générale de Roquefort 2012, Interprofession Lait de Brebis des Pyrénées-Atlantiques 2012).

\section{a) La matière grasse laitière}

La MG laitière est composée majoritairement de triglycérides formés d'une molécule de glycérol estérifiée par 3 AG. Un AG est constitué d'une chaîne hydrocarbonée $\left(-\mathrm{CH}_{2}\right.$ ou $\left.-\mathrm{CH}=\right)$ terminée d'une part, par un groupement carboxyle (-COOH) et, d'autre part, par un groupement méthyle $\left(-\mathrm{CH}_{3}\right)$. Les AG diffèrent par la longueur de leur chaîne, variant de 4 à 24 atomes de carbone, leur degré d'insaturation, c'est-à-dire le nombre de doubles liaisons, et le positionnement sur la chaîne et la configuration spatiale «cis » ou «trans » de leur(s) double(s) liaison(s).

Plus de 400 AG composent la MG laitière, dont 15 contribuent chacun pour plus de $1 \%$ des AG Totaux (AGT). Les AG à plus de 16 atomes de carbone $(\approx 60 \%$ des AGT) proviennent essentiellement de l'alimentation ou de la mobilisation des réserves corporelles. Le reste des AG est principalement synthétisé dans la glande mammaire par élongation des AG volatils issus des fermentations dans le rumen (Chilliard et al 2000, Chilliard et al 2007, Peyraud et al 2011).

\section{b) Les lactoprotéines}

Les protéines sont des macromolécules composées d'une ou plusieurs chaîne(s) d'acides aminés reliés par des liaisons peptidiques. Le lait contient des centaines de protéines différentes dont six lactoprotéines majeures (quatre caséines et deux protéines solubles). Le total des caséines $\alpha \mathrm{s} 1, \alpha \mathrm{s} 2, \beta$ et $\kappa$ représente 80 à $85 \%$ de la fraction protéique des laits de vache, chèvre et brebis. Les caséines, présentes sous forme de micelles, sont responsables de la couleur blanche du lait et jouent un rôle important en fabrication fromagère, notamment pour la coagulation. Les protéines solubles représentent le reste des lactoprotéines. Les principales sont l' $\alpha$ lactalbumine et la $\beta$-lactoglobuline, synthétisées dans la glande mammaire.

\section{2 / Principe de la quantification de la composition fine du lait par spectrométrie dans le moyen infrarouge}

La spectrométrie MIR est basée sur le principe d'absorption des rayonnements infrarouges par la matière organique. Les groupements fonctionnels des composants du lait absorbent la lumière à différentes longueurs d'onde qui leur sont spécifiques. Les régions spectrales d'intérêt se situent approximativement entre $1000 \mathrm{~cm}^{-1}$ et $3200 \mathrm{~cm}^{-1}$ (Bisgard Oldrup et al 2010).

Figure 1. Exemple d'un spectre dans le moyen infrarouge d'un échantillon de lait de vache : analyse avec un spectromètre MilkoScan FT6000 (Foss Electric, Hillerod, Danemark).

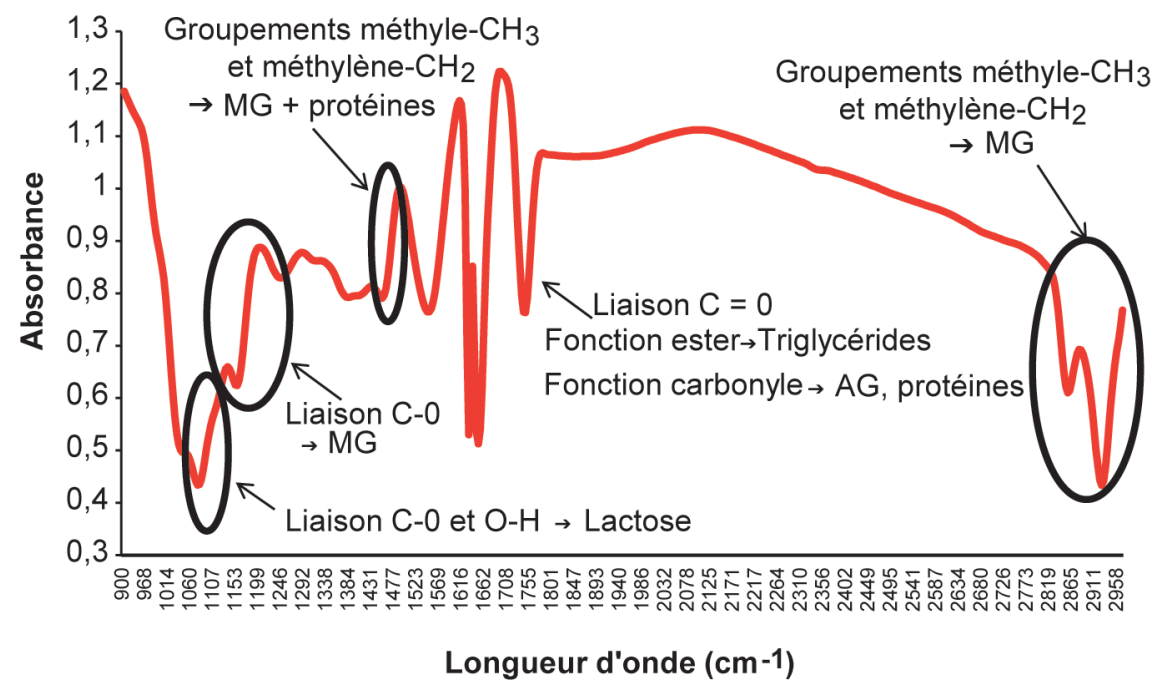

Chaque pic d'absorption correspondant à une liaison moléculaire (Bisgard Oldrup et al 2010), chaque molécule est donc caractérisée par plusieurs pics (figure 1). Les absorbances mesurées sont mises en relation, via un modèle statistique, avec les teneurs des différents composants déterminées par une méthode d'ancrage (figure 2). Ce modèle repose sur une régression de type « Partial Least Square » (PLS), permettant de traiter les cas où les individus sont moins nombreux que les variables explicatives et où ces dernières sont fortement corrélées entre elles. Par rapport à la régression sur composantes principales, la régression PLS permet de maximiser la corrélation entre les variables explicatives et les variables à expliquer (Tenenhaus 2002). Pour optimiser le modèle, différents prétraitements et méthodes de sélection de variables ont été testés. La combinaison d'un algorithme génétique, permettant la sélection des longueurs d'onde les plus informatives, et d'une régression PLS a été retenue pour la majorité des constituants (Ferrand-Calmels et al 2014).

Le modèle statistique est composé de coefficients à appliquer au résultat d'absorbance de chaque longueur d'onde du spectre sélectionnée, pour estimer les composés d'intérêt. Ces équations sont développées à partir d'un jeu dit d'étalonnage de quelques centaines d'échantillons constitué dans l'objectif de maximiser la variabilité des données (Bisgard Oldrup et al 2010), notamment pour les facteurs d'influence connus dans la littérature. La variabilité génétique (race, variants génétiques des caséines), alimentaire et physiologique des animaux (stade et rang de lactation), ainsi que celle des spectres et de la composition des laits (MG, MP, Comptages de Cellules Somatiques (CCS)) du jeu d'étalonnage doit être représentative des situations pré- 
Figure 2. Développement des équations d'estimation des teneurs en acides gras et protéines à partir des spectres dans le moyen infrarouge et évaluation de leur précision d'estimation sur le jeu de validation indépendant.

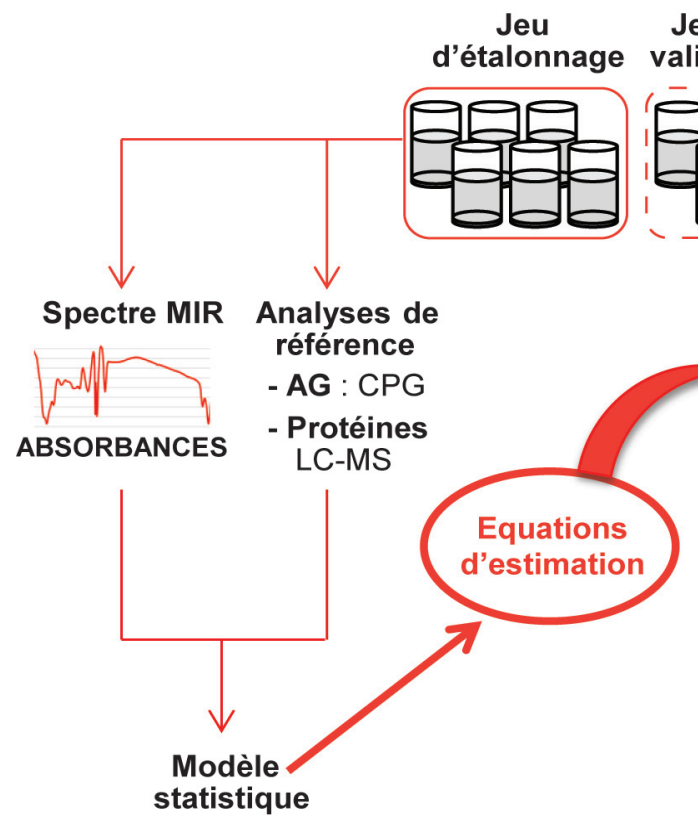

Jeu de

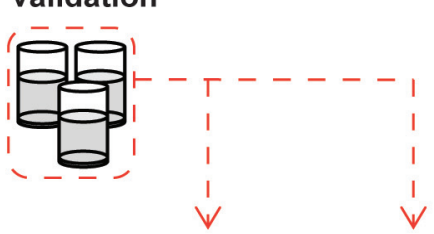

Spectre MIR Analyses de

CPG : Chromatographie en Phase Gazeuse.

LC-MS : Chromatographie Liquide couplée à la Spectrométrie de Masse.

sentes dans la population sur laquelle s'appliquera le modèle.

Les modèles sont validés selon la norme ISO 8196-2 | IDF 128-2 sur un jeu de validation indépendant afin d'évaluer leur précision d'estimation. Le biais moyen (d), la pente (b), les tests $t$ de Student pour d et b, l'écart-type résiduel de régression $\left(\mathrm{s}_{\mathrm{y}, \mathrm{x}}\right)$ et le coefficient de détermination $\left(\mathrm{R}^{2}\right)$ sont estimés à l'aide d'une régression linéaire : $\mathrm{y}=\mathrm{bx}+\mathrm{a}$, où $\mathrm{x}$ est la prédiction obtenue par MIR et y la valeur de référence. Le $\mathrm{R}^{2}$ évalue la qualité de l'ajustement, et l'écarttype résiduel exprimé en relatif par rapport à la teneur moyenne du composant $\left(\mathrm{s}_{\mathrm{y}, \mathrm{x}}\right.$ relatif), correspond à la précision d'estimation du modèle.

Les estimations sont considérées suffisamment précises pour être utilisées en routine quand le $\mathrm{s}_{\mathrm{y}, \mathrm{x}}$ relatif est inférieur à $5 \%$ et le $\mathrm{R}^{2}$ est supérieur 0,91 (Coppa et al 2010). Quand le $\mathrm{s}_{\mathrm{y}, \mathrm{x}}$ relatif est compris entre 5 et $10 \%$ et que le $\mathrm{R}^{2}$ est supérieur à 0,82 , il est conseillé d'utiliser ces équations uniquement dans un but analytique. Pour un $\mathrm{s}_{\mathrm{y}, \mathrm{x}}$ relatif compris entre 10 et $15 \%$ et un $\mathrm{R}^{2}$ supérieur à 0,70 , l'utilisation devrait être restreinte aux programmes de recherche et développement. Néanmoins, en fonction des objectifs ces bornes sont à moduler, notamment lorsque plusieurs mesures sont disponibles pour un même animal (Cecchinato et al 2009, Maurice-Van Eijnhoven et al 2013) ou lorsque le composant étudié présente une grande variabilité.

La qualité de la méthode d'ancrage est primordiale pour assurer une bonne des laits.

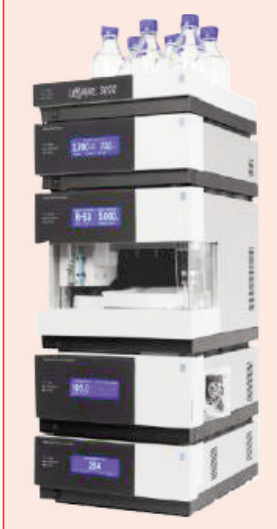

Chaîne chromatographique

« Ultimate 3000 » CDionex

\section{3 / Données utilisées pour le développement des équations PhénoFinlait}

\author{
a) Données utilisées pour la quantification \\ des acides gras
}

Les équations pour les $A G$ ont été développées à partir de données issues en majorité de stations expérimentales de l'INRA et collectées spécifiquement. Quelques données de fermes privées ont été utilisées quand la variabilité des données expérimentales n'était pas suffisamment représentative de la situation des populations françaises. Le jeu de données a été constitué intra-espèce de manière à travailler sur des laits de femelles de différentes races, à divers stades physiologiques, sur plusieurs régimes alimentaires par saison, voire plusieurs variants génétiques de caséines en caprins (Ferrand-Calmels et al 2014).

Le jeu de données « bovines » contenait 349 laits collectés au cours de l'hiver 2008-2009 et de l'été 2009 dans les stations INRA du Pin-au-Haras et de Mirecourt. Les vaches concernées étaient de races Montbéliarde, Holstein et croisées Holstein $\times$ Normande et de stades et rangs de lactation variés. Plusieurs régimes alimentaires par saison, à base d'ensilages de maïs et/ou d'herbe, de foin, et de pâturage de prairie temporaire ou de prairie permanente à flore variée, étaient représentés.

Chez les caprins, 332 laits ont été collectés entre 2008 et 2012 à la station INRA de Bourges et dans quatre élevages

Encadré. La LC-MS, méthode ultra-résolutive pour l'analyse de la fraction protéique

La LC-MS permet la séparation et l'identification de chaque fraction protéique individualisée présente dans le lait par comparaison entre leur masse mesurée et les masses théoriques de molécules répertoriées dans des bases de données pour chaque espèce. Cette méthode est relativement rapide et peu coûteuse et peut être employée sur des volumes conséquents d'échantillons. II est ainsi possible d'identifier et de quantifier chacune des lactoprotéines majeures présentes ainsi que leur variant(s) génétique(s) et isoformes d'épissage, leurs modifications post-traductionnelles et certains produits de protéolyse. Au total, respectivement 3000,2200 et 1700 masses moléculaires sont indexées pour les espèces bovine, caprine et ovine, montrant l'ultra-résolution de cette méthode faisant l'objet d'un processus de normalisation ICAR-FIL.

Spectromètre de masse " micrOTOF ${ }^{\mathrm{TM}}$ ॥l focus » OBruker Daltonics

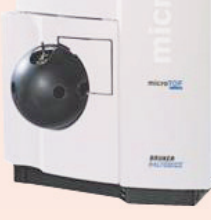


privés. Les chèvres Alpines et Saanens, recevaient des rations contenant du foin (graminées et/ou légumineuses) séché en grange ou non, du pâturage, de l'enrubannage, de l'ensilage de maïs et de la luzerne déshydratée.

Chez les ovins, 200 laits ont été collectés en 2008-2009 au domaine INRA de La Fage et dans trois élevages privés sur des brebis Lacaunes, Manech Tête Rousse (Manech) et Basco-Béarnaises. Les systèmes alimentaires étaient divers, avec la présence d'ensilages d'herbe et de maïs, de foin de graminées et/ou de légumineuses (dont luzerne), de paille, de pâturage et de divers concentrés.

Deux tiers des données ont constitué le jeu d'étalonnage des équations qui ont ensuite été validées sur le tiers restant. Ces jeux d'étalonnage couvraient correctement la diversité des situations d'élevage françaises (Ferrand-Calmels et al 2014).

Deux échantillons de lait ont été prélevés par animal et par traite. L'un, après ajout de bronopol (à la concentration de $0,02 \%$ final) - conservateur dont l'effet sur le spectre est minime (Bisgard Oldrup et al 2010) - a été analysé par spectrométrie MIR au LILANO de St Lô (appareil MilkoScan ${ }^{\mathrm{TM}}$ FT6000) et à Maroeuil (appareil Bentley FTS) pour les bovins, au LILCO de Surgères (MilkoScan ${ }^{\mathrm{TM}}$ FT6000) pour les caprins et au LIAL MC d'Aurillac (MilkoScan ${ }^{\mathrm{TM}}$ FT6000) pour les ovins. L'autre a été congelé à $-20^{\circ} \mathrm{C}$, puis analysé par CPG selon les normes ISO 15884/15885 au Laboratoire Analyses Alimentaires Recherche Fromagère (LARF) de Mamirolle (Kramer et al 1997).

La CPG a permis d'identifier 68 AG. Au total, 92 équations d'estimation d'AG, de groupes d'AG ou de ratios d'AG ont été développées en bovins, 91 en ovins et 110 en caprins. Les teneurs en $\mathrm{AG}$, estimées en pourcentage du lait pour obtenir une meilleure précision (Soyeurt et al 2006), ont été converties en pourcentage des AGT de la manière suivante :

\section{AG (g/100g d'AGT) = 100*AG (g/100g de lait)/(0,95*MG (g/100g de lait))}

0,95 correspondant à la part des AG dans la MG (Bisgard Oldrup et al 2010). De cette façon, la perte de précision d'estimation est faible, conformément aux résultats de Soyeurt et al (2011).

\section{b) Données utilisées pour la quantification des lactoprotéines}

Les laits utilisés pour l'étalonnage des modèles provenaient de la LactoBanque PhénoFinlait, dont la constitution est décrite au paragraphe 2.3 . Le jeu de données « bovines » était constitué de 280 échantillons de lait répartis équitablement entre races. Pour les ovins, 119 échantillons de lait de Lacaunes et 40 laits de Manechs constituaient le jeu de données. En caprins, les équations sont en cours de développement sur 287 laits de chèvres Alpines et Saanens et ne seront donc pas détaillées dans cet article.

Les données spectrales ont été extraites par les laboratoires d'analyses du lait. Un échantillon du même lait a été analysé en LC-MS à l'INRA de Jouy-en-Josas (chaîne chromatographique «Ultimate $3000 »$ Dionex interfacée avec un spectromètre de masse de type ESI-TOF (analyseur haute résolution à temps de vol et à ionisation par électronébulisation), « microTOF ${ }^{\mathrm{TM}}$ II focus », Bruker Daltonics). Deux tiers des données ont servi à l'étalonnage du modèle, et un tiers à sa validation. Neuf équations ont été développées pour les bovins et les ovins : MP, total des caséines, chacune des 4 caséines $(\alpha \mathrm{s} 1, \alpha \mathrm{s} 2, \beta, \kappa), \alpha$-lactalbumine et $\beta$-lactoglobuline et la somme de ces deux protéines solubles.

La cinétique de protéolyse, à laquelle le lait est sensible, des laits de bovins a été étudiée à l'INRA de Jouy-en-Josas, permettant de réaffecter la part protéolysée imputée à chaque fraction protéique. Ainsi, pour les bovins, deux jeux d'équations ont été développés : un avec réaffectation de la protéolyse et un sans réaffectation. Réaffecter la protéolyse permet d'estimer avec une meilleure précision la composition du lait natif et d'améliorer la performance des équations. Cela conduit à une meilleure approche $\mathrm{du}$ déterminisme génétique de la composition fine en lactoprotéines et de ses facteurs d'influence. Les équations présentées dans le tableau 1 prennent en compte la réaffectation de la protéolyse. Toutefois, dans le cadre d'une utilisation par les collecteurs transformateurs, la composition du lait livré devra être évaluée sans réaffectation de la protéolyse afin d'estimer le plus précisément possible la composition du lait réellement livré.

\section{4 / Principaux résultats}

\section{a) Equations d'estimation des teneurs en acides gras}

Parmi les équations bovines, 17 ont une très bonne précision $\left(\mathrm{R}^{2}>0,91 ; \mathrm{s}_{\mathrm{y}, \mathrm{x}}\right.$ relatif $<5 \%$ ), 10 ont une bonne précision $\left(\mathrm{R}^{2}>0,82 ; 5<\mathrm{s}_{\mathrm{y}, \mathrm{x}}\right.$ relatif $\left.<10 \%\right)$ et 27 ont une précision correcte $\left(\mathrm{R}^{2}>0,70 ; 10<\mathrm{S}_{\mathrm{y}, \mathrm{x}}\right.$ relatif $<15 \%$ ). Respectivement chez les ovins et les caprins 15 et 20 équations sont très précises, 12 et 23 sont précises, et 23 et 24 sont assez précises (FerrandCalmels et al 2014). Les principaux résultats sont présentés dans le tableau 1.
Quelle que soit l'espèce, les estimations les plus précises $\left(\mathrm{R}^{2}>0,91 ; \mathrm{s}_{\mathrm{y}, \mathrm{x}}\right.$ relatif $<$ $5 \%$ ) sont obtenues sur les AG présents en concentration moyenne ou élevée dans le lait: AG Saturés (AGS) jusqu'à 16 atomes de carbone et les AG MonoInsaturés (AGMI) à 18 atomes de carbone (C18:1). Des conclusions similaires ont été obtenues par Soyeurt et al (2006) et par Coppa et al (2010).

Pour les laits de bovins, les équations développées sur des spectres issus d'analyseur Foss MilkoScan ${ }^{\mathrm{TM}}$ FT6000 sont plus précises que celles étalonnées sur des spectres d'analyseur Bentley FTS. Cela s'explique par le nombre de données disponibles plus important sur ce type d'appareil (150 pour Bentley vs 350 pour Foss). Néanmoins, quelle que soit la marque d'analyseur concerné, la précision des équations développées dans PhénoFinlait est comparable à celle des équations obtenues à partir de laits de vaches de races Holstein, Normande, Montbéliarde, Blanc Bleu Belge mixte, Jersiaise et Pie-Rouge (Soyeurt et al 2011) et elle est meilleure que celle des équations obtenues à partir de laits de vaches de race Brown-Swiss (De Marchi et al 2011), Dutch Friesian, Meuse-RhineYssel, Groningen White Headed et Jersiaise (Maurice-Van Eijnidhoven et al 2013), non représentées dans PhénoFinlait.

Pour les petits ruminants, aucune étude existante ne permet de comparer nos résultats. Cependant, la précision est comparable à celle des équations bovines, voire meilleure pour certains AG présents en petite quantité, comme les AG PolyInsaturés (AGPI).

\section{b) Equations d'estimation des teneurs en lactoprotéines}

Pour les bovins et les ovins, les équations obtenues pour les caséines sont plus précises que pour les protéines solubles (tableau 1). Les protéines présentes en plus grande quantité sont les mieux estimées. Ainsi la somme des caséines est mieux estimée que chaque caséine prise individuellement. Il en est de même pour les protéines solubles.

Pour les laits de bovins, le total des caséines et la caséine $\beta$ sont estimés avec une très bonne précision $\left(\mathrm{R}^{2}>0,91\right.$ et $\mathrm{s}_{\mathrm{y}, \mathrm{x}}<5 \%$ ), et les caséines $\alpha \mathrm{s} 1$, $\alpha \mathrm{s} 2$ et $\kappa$ avec une bonne précision $\left(\mathrm{R}^{2}>0,82\right.$ et $\mathrm{s}_{\mathrm{y}, \mathrm{x}}$ entre 5 et $10 \%$ ). La précision d'estimation des protéines solubles est plus faible, surtout pour l' $\alpha$-lactalbumine. Parmi les équipes ayant publié sur le sujet, les équations développées en $\mathrm{g} / 100 \mathrm{~g}$ de MP par Rutten et al (2011) présentent un $\mathrm{R}^{2}$ inférieur à 0,30 pour toutes les caséines. Les équations développées en g/L de lait par Bonfatti et al (2011) sur des échantillons de lait de vaches de 
Tableau 1. Paramètres statistiques des équations développées en g/100g de lait pour le jeu de validation indépendant en bovins, ovins et caprins.

\begin{tabular}{|c|c|c|c|c|}
\hline & & $\begin{array}{l}\text { Composants estimés } \\
\text { avec une très bonne précision } \\
\left(R^{2}>0,91 \text { et } s_{y, x} \text { relatif }<5 \%\right)\end{array}$ & $\begin{array}{c}\text { Composants estimés } \\
\text { avec une bonne précision } \\
\left(\mathrm{R}^{2}>0,82 \text { et } 5 \%<\mathrm{s}_{\mathrm{y}, \mathrm{x}} \text { relatif }<10 \%\right)\end{array}$ & $\begin{array}{c}\text { Composants estimés } \\
\text { avec une précision correcte } \\
\left(R^{2}>0,70 \text { et } 10 \%<s_{y, x} \text { relatif }<15 \%\right)\end{array}$ \\
\hline \multirow[t]{2}{*}{ Bovins } & Acides Gras & $\begin{array}{c}\text { MG, } \\
\text { C4:0, C6:0, C8:0, } \\
\text { AGS, AGMI, AGI, } \\
\text { SCFA, MCFA, } \\
\text { Somme C4:0 + C6:0, } \\
\text { AG pairs de C4 à C10, } \\
\text { AG pairs de C4 à C12, } \\
\text { AG pairs de C4 à C14, } \\
\text { AG à } 16 \text { carbones ou moins, } \\
\text { AGS à } 16 \text { carbones ou moins } \\
\text { AGS pairs à 16 C ou moins, } \\
\text { Somme C12:0 + 4C14:0 + C16:0 }\end{array}$ & $\begin{array}{c}\text { C10:0, C12:0, C14:0, C16:0, } \\
\text { C18:1 c9, } \\
\text { LCFA, } \\
\text { Total des C18:1, } \\
\text { Total des C18:1 cis, } \\
\text { Indice d'élongation, } \\
\text { Indice d'athérogénicité }\end{array}$ & $\begin{array}{c}\text { C11:0, C15:0, C15:0 iso, } \\
\text { C17:0, C18:0, C20:0, } \\
\text { C17:1 c10, C18:1 c15, } \\
\text { C18:1 t12, C18:1 t16, } \\
\text { C18:2 c9 c12, } \\
\text { AGPI, AGPI/AGS } \\
\text { AG trans, Total des C18:1trans, } \\
\text { Total des C18:2, } \\
\text { Total des C18:2 } \omega 6, \\
\text { AG } \omega 3, \text { AG } \omega 6, \\
\text { AG } \omega 7, \text { AG } \omega 7 \text { cis, } \\
\text { AG impairs C5 à C11, } \\
\text { AG impairs C5 à C15, } \\
\text { AG impairs C13 à C17, } \\
\text { C18:1/C16:0, C18:1c9/C16:0, } \\
\text { Index de désaturation } C 16,\end{array}$ \\
\hline & Protéines & $\begin{array}{c}\text { MP, } \\
\text { Total des caséines, Caséine } \beta\end{array}$ & Caséine as1, Caséine as2, Caséine $\mathrm{k}$ & $\begin{array}{c}\text { Somme } \alpha \text {-lactalbumine }+ \\
\beta \text {-lactoglobuline, } \beta \text {-lactoglobuline }\end{array}$ \\
\hline Caprins & Acides Gras & $\begin{array}{c}\text { MG, } \\
\text { C4:0, C6:0, C8:0, C10:0, C16:0, } \\
\text { C22:1 w9, C20:3 w3 } \\
\text { AGS, AGMI, AGI, } \\
\text { Somme C4:0 + C6:0, } \\
\text { AG pairs de C4 à C10, } \\
\text { AG pairs de C4 à C12, } \\
\text { AG pairs de C4 à C14, } \\
\text { AG à } 16 \text { carbones ou moins, } \\
\text { AGS à } 16 \text { carbones ou moins } \\
\text { Total des C18:1, } \\
\text { Total des C18:1 cis }\end{array}$ & $\begin{array}{c}\text { C12:0, C14:0, } \\
\text { C17:0, C17:0 iso, C17:0 anteiso, } \\
\text { C18:1 c9, C18:2 c9 c12, } \\
\text { AGPI, AGPI/AGS } \\
\text { Total des C18:1 cis, } \\
\text { Total des C18:2, } \\
\text { Total des C18:2 } \omega 6, \\
\text { Total des C18:2 trans, } \\
\text { AG } \omega 6, \text { AG } \omega 7, \\
\text { AG impairs C5 à C15, } \\
\text { AG impairs C13 à C17, } \\
\text { Indice d'élongation, } \\
\text { Indice d'athérogénicité } \\
\text { C18:1/C16:0, C18:1c9/C16:0, } \\
\text { C16:0/AGS } \\
\text { MCFA/C16, MCFA/C12C14C16 }\end{array}$ & $\begin{array}{c}\text { C11:0, C15:0, C15:0 iso, C15:0 anteiso, } \\
\text { C16:0 iso, C18:0, C20:0 } \\
\text { C10:1, C17:1 c10, } \\
\text { C18:1 c11, C18:1 c15, } \\
\text { C18:1 t16, C20:1 c11, } \\
\text { C20:4 } \omega 6, \text { C22:5 } \omega 3 \text {, } \\
\text { Total C18:1 trans, Total C20:1, } \\
\text { AG } \omega 3, \text { AG } \omega 7 \text { cis, } \\
\text { AG trans, } \\
\text { AG impairs C5 à C11, } \\
\text { Index désaturation C16, } \\
\text { C18:2 c9 c12/C18:3 } c 9 c 12 \text { c15, } \\
\text { AG } \omega 6 / A G ~ \omega 3\end{array}$ \\
\hline \multirow[t]{2}{*}{ Ovins } & Acides Gras & $\begin{array}{c}\text { MG, } \\
\text { C4:0, C6:0, C8:0, } \\
\text { AGS, AGMI, AGI, } \\
\text { Somme C4:0 + C6:0, } \\
\text { AG pairs de C4 à C10, } \\
\text { AG pairs de C4 à C12, } \\
\text { AG pairs de C4 à C14, } \\
\text { AG à } 16 \text { carbones ou moins, } \\
\text { AGS à } 16 \text { carbones ou moins } \\
\text { Total des C18:1, } \\
\text { Somme C12:0 + } 4 \text { C14:0 }+ \text { C16:0 }\end{array}$ & $\begin{array}{c}\text { C10:0, C12:0, C14:0, C16:0, } \\
\text { C18:1 c9, } \\
\text { AGPI, AGPI/AGS } \\
\text { Total des C18:1 cis, } \\
\text { Total des C18:2, } \\
\text { AG impairs C13 à C17, } \\
\text { Indice d'élongation, } \\
\text { Indice d'athérogénicité }\end{array}$ & $\begin{array}{c}\text { C11:0, C15:0, C15:0 anteiso, C16:0 iso, } \\
\text { C17:0, C17:0 iso, C17:0 anteiso, } \\
\text { C18:0, } \\
\text { C17:1 } c 10, C 18: 1 c 11, C 18: 1 t 16, \\
\text { C18:3 } c 9 c 12 c 15, \\
\text { Total des C18:2 } \omega 6, \\
\text { AG } \omega 3, A G \omega 6, \\
\text { AG } \omega 7, A G \omega 7 \text { cis, } \\
\text { AG impairs C5 à C11, } \\
\text { AG impairs C5 à C15, } \\
\text { C18:1/C16:0, C18:1c9/C16:0, } \\
\text { Index de désaturation } C 16, \\
\text { Index de désaturation } C 18\end{array}$ \\
\hline & Protéines & $\begin{array}{l}\text { MP, Total des caséines, } \\
\text { Caséine } \beta \text {, Caséine as } 1\end{array}$ & Caséine as2, Caséine $\mathrm{k}$ & $\begin{array}{c}\text { Somme } \alpha \text {-lactalbumine }+ \\
\beta \text {-lactoglobuline, } \beta \text {-lactoglobuline }\end{array}$ \\
\hline
\end{tabular}

AGS : Acides Gras Saturés ; AGI : Acides Gras Insaturés ; AGMI : Acides Gras Monolnsaturés ; AGPI : Acides Gras Polylnsaturés ; SCFA : Acides Gras à Chaîne Courte (4 à 10 carbones) ; MCFA : Acides Gras à Chaîne Moyenne (11 à 16 carbones) ;

LCFA : Acides Gras à Chaîne Longue (17 carbones et plus) ;

Index de désaturation $C 16=C 16: 1 c 9 /(C 16: 0+C 16: 1 c 9) ;$ Index de désaturation $C 18=C 18: 1 c 9 /(C 18: 0+C 18: 1 c 9)$;

Indice d'élongation $=(C 8: 0+C 10: 0+C 12: 0+C 14: 0) /(C 4: 0+C 6: 0) ;$ Indice d'athérogénicité $=(C 12: 0+4 * C 14: 0+C 16: 0) / A G I$.

race Simmental présentent un $\mathrm{R}^{2}$ compris selon la protéine entre 0,31 et 0,78 . Deux hypothèses expliqueraient les meilleurs résultats obtenus ici. D'une part, les méthodes utilisées, HPLC (Bonfatti et al 2011) et électrophorèse (Rutten et al 2011), sont moins résolutives et précises que la LC-MS. D’autre part, la réaffecta- tion de la protéolyse en bovins améliore les résultats. En effet, les équations qui présentent les plus grands écarts de performances avec les résultats de ces équipes concernent les caséines $\alpha \mathrm{s} 1, \beta$ et $\kappa$, qui sont les plus touchées par la protéolyse (au total $92 \%$ de la protéolyse leur est réattribuée).
Pour les laits d'ovins, sans réaffectation de la protéolyse, les performances des équations sont satisfaisantes. Comme pour les laits de bovins, la caséine $\beta$ est la mieux estimée et l'équation d'estimation de l' $\alpha$-lactalbumine est peu précise. Il n'existe pas d'étude comparable dans la littérature. 


\section{2 / Le dispositif PhénoFinlait}

Le dispositif PhénoFinlait a permis de collecter massivement des données dans les élevages commerciaux, dont les spectres MIR des laits sur lesquels les équations d'estimation décrites ci-dessus ont été appliquées. Cette collecte a été réalisée selon un protocole multiespèces établi en 2009 par l'Institut de l'Élevage et l'INRA en partenariat avec des experts de terrain : Entreprises de Conseil en Elevage Laitier (ECEL), laboratoires d'analyse du lait, UNCEIA (Union Nationale des Coopératives d'Elevage et d'Insémination Animale), Comité National Brebis Laitières, Labogéna, Capgènes, Actalia Cecalait et les constructeurs de spectromètres Bentley Instruments et Foss. Les données collectées sont de plusieurs types : $i$ ) données issues du contrôle laitier (données spectrales et analyses laitières : poids de lait, TB, TP, CCS, urée, lactose au jour du contrôle), ii) enquêtes sur l'alimentation des animaux au jour du contrôle et iii) données des Systèmes Nationaux d'Information Génétique (SNIG) : race, généalogie et carrière des animaux. Des échantillons de laits congelés pour des analyses ultérieures et des échantillons de sang pour le génotypage des femelles sélectionnées ont complété cette collecte. Ces données sont rassemblées dans une base de données dédiée à PhénoFinlait et destinée à l'étude des facteurs influençant la composition du lait.

\section{1 / Mise en place de la collecte}

\section{a) Choix des élevages}

Les 1 157, 209 et 162 élevages bovins, caprins et ovins respectivement choisis étaient adhérents au contrôle laitier et ont été sélectionnés en fonction de leur taille, de leur localisation géographique, de façon à couvrir la diversité des principaux systèmes d'élevages français, ainsi que la diversité génétique en tenant compte de la race des femelles et de leur généalogie. Les laboratoires d'analyses du lait devaient être équipés pour le stockage et l'export des spectres MIR.

Les élevages bovins étaient situés dans 16 départements des bassins laitiers du Grand Ouest (Calvados, Ille-et-Vilaine, Loire-Atlantique, Maine-et-Loire, Manche, Mayenne, Orne, Sarthe), du Nord (Nord, Pas-de-Calais) et de l'Est (Côte d'Or, Doubs, Jura, Bas-Rhin, Haut-Rhin, Territoire de Belfort). Au total 84000 vaches Holsteins, Montbéliardes et Normandes ont été concernées.

En caprins, 71000 chèvres Alpines et Saanens ont été concernées dans 8 départements autour du bassin Poitou-Charentes (Charente, Charente-Maritime, Indre, Indre-et-Loire, Maine-et-Loire, Deux-
Sèvres, Vendée et Vienne) et dans l'Aveyron. En ovins, la collecte a concerné 33600 brebis sur 3 départements pour couvrir 2 bassins de production : le Rayon où la race Lacaune est présente, et les $\mathrm{P}-\mathrm{A}$ avec la race Manech (figure 3).

\section{b) Les femelles PhénoFinlait}

Chaque élevage devait posséder un minimum de 5 à 10 filles (selon l'espèce) des pères sélectionnés (15 taureaux, 10 boucs et 32 béliers par race) pour être représentatifs de la diversité génétique de la race. Un total de 100 à 200 filles par père était visé pour permettre la construction d'un dispositif de détection de «Quantitative Trait Locus» (QTL). Les filles de ces pères sont dites « femelles PhénoFinlait » et entraient en $1^{\text {ere }}$ ou $2^{\text {ème }}$ lactation fin 2009-début 2010. Elles ont fait l'objet d'un suivi alimentaire individuel et de prélèvements de lait et de sang.

\section{c) Période de collecte}

Dans les élevages bovins, 6645 enquêtes ont été renseignées entre novembre 2009 et octobre 2010, principalement sur deux périodes distinctes pour éviter les transitions alimentaires : une période dite « d'hiver » (52\% des enquêtes) avec des rations à base de fourrages conservés et une période dite « d'été » $(48 \%$ des enquêtes) incluant, selon les systèmes d'exploitation, une part variable d'herbe pâturée. Les limites des deux périodes différaient selon la région, pour tenir compte de leurs spécificités pédoclimatiques.

Dans les élevages caprins, 895 enquêtes ont été réalisées entre février et septembre 2010, soit en moyenne un peu plus de 4 par élevage. Enfin, 968 enquêtes ont été réalisées entre décembre 2009 et juillet 2010 dans les élevages ovins (en raison de la saisonnalité de la Production Laitière (PL) dans cette espèce, la période de collecte se terminant au début de l'été). Ces enquêtes s'étalaient sur une période hivernale concernant des régimes principalement à base de fourrages conservés et une période printanière pendant laquelle une part d'herbe pâturée est incluse dans la ration. Ainsi, les animaux ont été suivis sur une grande partie de la lactation, à des périodes où les systèmes d'alimentation sont variés.

\section{2 / Les contrôles PhénoFinlait}

Un « contrôle PhénoFinlait » est un contrôle laitier officiel durant lequel le technicien a rempli une enquête d'alimentation. Les données collectées concernaient les analyses laitières et l'alimentation des animaux (figure 4) et ont été stockées dans la base de données PhénoFinlait au Centre de Traitement de l'Information Génétique (CTIG) de l'INRA de Jouy-en-Josas. Tout au long de la collecte, un suivi sous forme de tableaux de bord a permis d'assurer l'exhaustivité et la qualité des données.

Les contrôles PhénoFinlait ont été réalisés par plus de 500 techniciens des ECEL qui ont prélevé les échantillons de lait et renseigné l'enquête d'alimentation. L'enquête, saisie à l'aide d'un outil Access ${ }^{\circledR}$ spécifique pour lequel les techniciens ont reçu une formation, était automatiquement exportée vers la base de données. Cet outil, composé de formulaires informatisés développés par l'Institut de l'Élevage, a permis de recueillir de manière standardisée les caractéristiques des aliments utilisés par l'éleveur autour du contrôle (pâturages, fourrages conservés et affouragés, aliments concentrés du

Figure 3. Localisation géographique des élevages enquêtés.

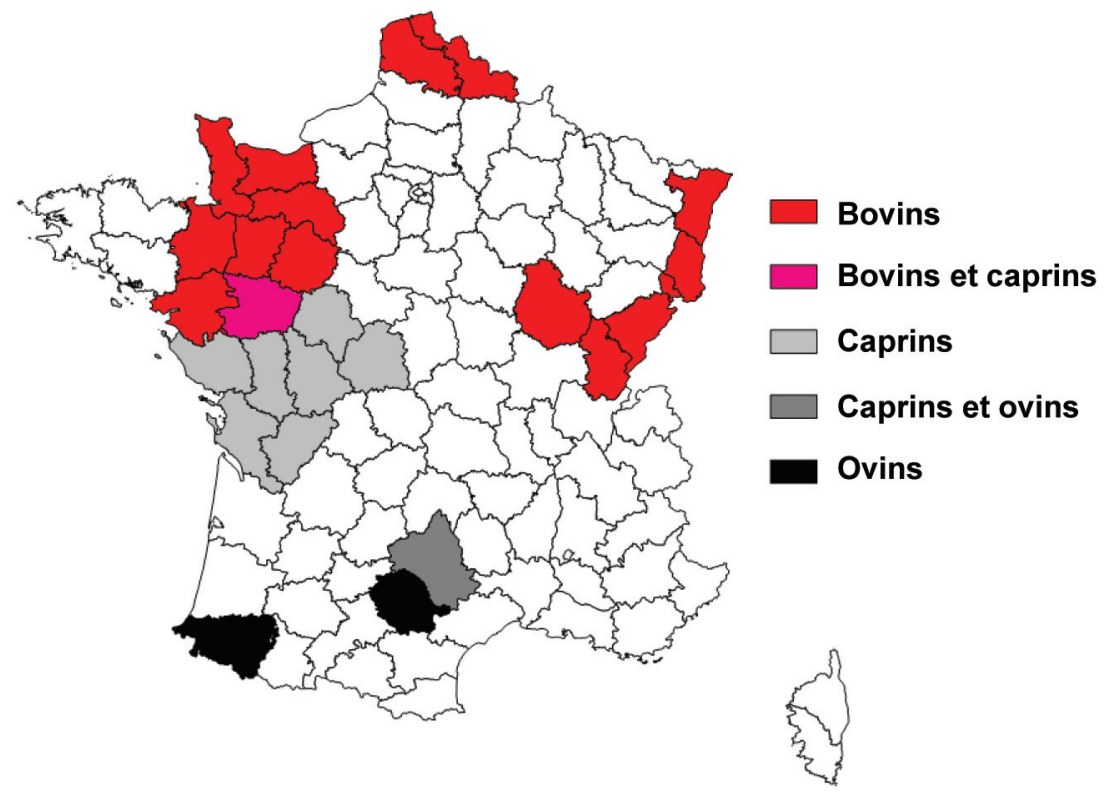


Figure 4. Dispositif PhénoFinlait pour la collecte des données.

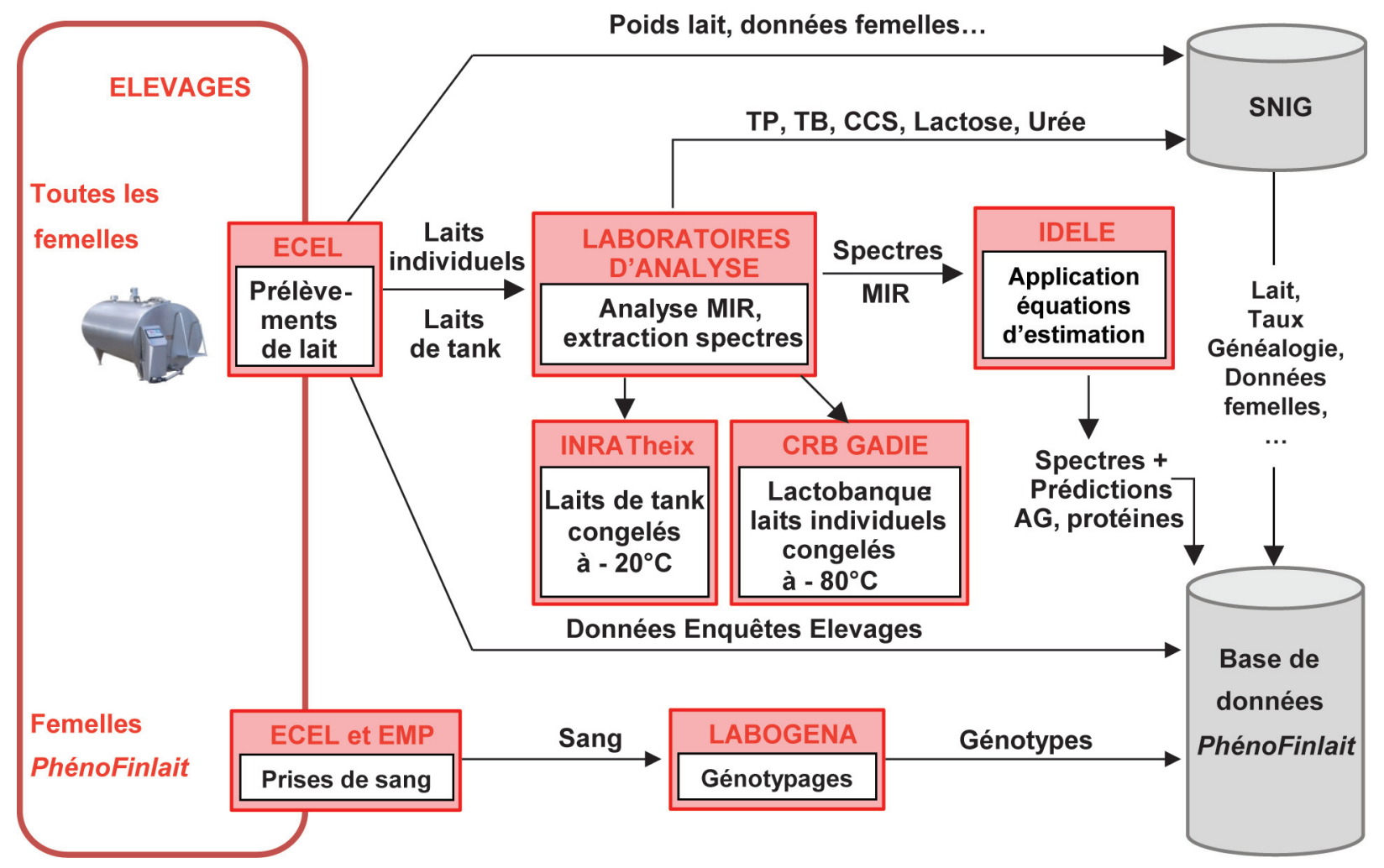

CRB GADIE : Centre de Ressources Biologiques pour la Génomique des Animaux Domestiques et d'Intérêt Economique ; ECEL : Entreprise de Conseil en Elevage Laitier; EMP : Entreprise de Mise en Place ; IDELE : Institut de I'Elevage ; MIR : Moyen InfraRouge ; SNIG : Système National d'Information Génétique.

commerce et leurs étiquettes et matières premières distribuées en l'état), la composition de la ration collective distribuée au troupeau ou au lot (fourrages et concentrés distribués collectivement), les règles de distribution individuelle de concentrés et l'estimation des refus. Pour les bovins, un formulaire supplémentaire permettait de renseigner systématiquement, pour chaque aliment, les quantités précises distribuées individuellement à chaque femelle PhénoFinlait. Pour les petits ruminants, l'alimentation étant raisonnée au lot ou au troupeau, cette approche individuelle n'était pas possible. Des événements sanitaires susceptibles de modifier la composition du lait pouvaient également être notifiés. Les échantillons de laits ont été envoyés aux laboratoires d'analyse. Les spectres MIR ont été établis puis exportés vers la base de données PhénoFinlait. Les taux (TB, TP, CCS, Urée, Lactose) ont été mesurés au laboratoire puis stockés au niveau du SNIG. Près de 445000 spectres MIR et performances laitières individuelles affiliées ont été enregistrées en bovins, 270000 en caprins et 120000 en ovins.

Une étude préliminaire à PhénoFinlait, réalisée par Actalia Cecalait, a montré l'existence d'un décalage spectral causé par un biais entre analyseurs et pour un même analyseur au cours du temps. Un dispositif de normalisation des données a été mis en place au moyen de laits de contrôle analysés simultanément par chaque analyseur du dispositif tout au long de la phase de collecte des spectres MIR. Ces laits, également analysés en $\mathrm{CPG}$, ont permis de quantifier le biais imputable à chaque analyseur à une date donnée et ainsi de réaliser un recalage additif des données (Leray et al 2011). En pratique, pour chaque analyse de lait de contrôle, les estimations des concentrations en chaque AG (à partir des équations) ont été établies sur la base de six analyses MIR consécutives et ont été moyennées. Pour chaque combinaison (AG, espèces, analyseur, lait de contrôle) la constante de correction a été définie comme l'écart entre la valeur obtenue par analyse CPG et la valeur moyenne estimée. Ensuite pour chaque échantillon de lait PhénoFinlait, l'estimation à partir des équations de la concentration en chaque AG a été corrigée par addition de la constante de correction établie à partir du lait de contrôle le plus proche analysé sur le même analyseur.

\section{3 / Collecte d'échantillons bio- logiques}

Des prises de sang ont été réalisées, par les techniciens des Entreprises de Sélection (ES), et des ECEL en caprins, sur les femelles PhénoFinlait puis envoyées à Labogéna pour stockage en vu d'un géno- typage avec une puce à 50k d'Illumina. Ces puces (une par espèce) contiennent plus de 50000 marqueurs SNP (« Single Nucleotide Polymorphism » : polymorphisme dû à la variation d'un seul nucléotide) répartis sur l'ensemble du génome. Au total, 8444 vaches (2 415 Montbéliardes, 2804 Normandes et 3225 Holsteins), 2246 chèvres (1 309 Alpines et 937 Saanens) et 1914 brebis (1 188 Lacaunes et 726 Manechs) ont été génotypées. Ces génotypes ont été utilisés pour l'étude des déterminants génétiques de la composition fine du lait. Les résultats de cette étude sont présentés dans ce numéro par Boichard et al (2014).

Lors d'un contrôle PhénoFinlait hivernal, 9180,1075 et 9882 échantillons de laits individuels de bovins, caprins et ovins respectivement ont été recueillis à raison de 3 aliquotes de $2 \mathrm{~mL}$ par femelle PhénoFinlait, analysés en MIR dans les 48 heures puis congelés à $-20^{\circ} \mathrm{C}$ dans les laboratoires. Ils ont ensuite été transférés au CRB-GADIE de Jouy-enJosas pour y être conservés à $-80^{\circ} \mathrm{C}$ et constituer la LactoBanque PhénoFinlait.

Dans chaque élevage bovin et caprin, 2 échantillons de $30 \mathrm{~mL}$ de lait de mélange ont été prélevés dans le réservoir réfrigéré lors d'un contrôle PhénoFinlait à chaque période d'alimentation (hiver et été) puis congelés à $-20^{\circ} \mathrm{C}$. Dans chaque 
élevage ovin, 3 échantillons de lait de mélange ont été analysés en MIR à chaque contrôle PhénoFinlait et un échantillon a été prélevé et congelé à $-20^{\circ} \mathrm{C}$ à chaque période d'alimentation (hiver et été). L'ensemble de ces 2149,350 et 2530 échantillons de laits de mélange en bovins, caprins et ovins ont été transférés à l'INRA de Theix pour une étude spécifique des méthodes d'analyse spectrale dans l'infrarouge (Valenti et al 2013).

\section{3 / Les données collectées : reflet d'une grande diversité de systèmes laitiers}

\section{1 / Les élevages PhénoFinlait}

\section{a) Caractéristiques des troupeaux}

La taille des troupeaux varie selon l'espèce et le bassin de production. En moyenne, 73 vaches composent les troupeaux bovins. Les troupeaux caprins et ovins sont de même taille : en moyenne de 341 chèvres ou brebis. Les troupeaux bovins du bassin Nord sont les plus grands : 82 vaches en moyenne contre 75 dans l'Ouest et 64 dans l'Est. Les troupeaux caprins sont de même taille en Aveyron et dans la zone Vendée - Poitou-Charentes - Centre : 347 chèvres vs 340 en moyenne. Enfin, les troupeaux pyrénéens ovins sont plus petits que dans le Rayon : 259 brebis vs 392.

Chez les ovins, les deux races ne se retrouvent pas dans la même zone de production. Dans le Rayon, on ne trouve que des brebis Lacaunes tandis que dans les P-A il n'y a que des Manechs. Au contraire, un tiers des élevages bovins est mixte. Ces troupeaux sont surtout composés de Holsteins et Normandes, parfois de Holsteins et Montbéliardes. Une trentaine d'élevages dispose des trois races. Finalement, la race Holstein est présente dans $61 \%$ des troupeaux, contre $43 \%$ pour la race Normande et $33 \%$ pour la race Montbéliarde. La part de troupeaux mixtes est plus modeste en caprins : seulement $13 \%$ des élevages combinent des chèvres Alpines et Saanens.

Les troupeaux bovins sont rarement conduits en lots. En revanche, c'est une pratique courante dans les élevages ovins et surtout caprins où respectivement 13 et $66 \%$ des troupeaux sont conduits en plusieurs lots correspondant généralement à des stratégies alimentaires différentes. Cette pratique permet de mieux ajuster les apports aux besoins moyens du lot, l'alimentation étant raisonnée de façon collective. En ovins, les lots se distinguent généralement par la parité (primipares vs multipares) et/ou par le stade physiologique des brebis (en lien avec les cycles de reproduction). En règle générale, la conduite en lots concerne tout ou partie de la phase hivernale en bergerie, l'ensemble des brebis étant conduit en commun lors de la mise à l'herbe.

\section{b) Caractéristiques des femelles}

Pour les bovins, 23, 31 et $46 \%$ des vaches sont respectivement de races Montbéliarde, Normande et Holstein. Pour les caprins, les effectifs sont équilibrés : $51 \%$ des chèvres sont de race Alpine et $49 \%$ de race Saanen. Pour les ovins, $73 \%$ des brebis sont de race Lacaune et $27 \%$ de race Manech.

En bovins, le rang moyen de lactation est de 2,4 lactations et le taux de primipares moyen de $35 \%$. En race Montbéliarde, la longévité est un peu supérieure à celle des deux autres races : $33 \%$ de primipares et 2,6 lactations en moyenne comparativement aux vaches Normandes (35\% de primipares et 2,4 lactations) et Holsteins $(36,5 \%$ de primipares et 2,3 lactations). En caprins, le taux de primipares est de $34 \%$ en race Alpine et $37 \%$ en race Saanen. Le rang de lactation moyen est très proche entre races : 2,6 lactations en race Alpine et 2,5 en race Saanen. Environ 30\% des chèvres ont mis bas à contre-saison. En ovins, la part de primipares est de $32,7 \%$ en race Lacaune et $31,1 \%$ en race Manech. Soulignons que la collecte PhénoFinlait $n$ 'a concerné que les brebis en $1^{\text {ère }}$ et $2^{\text {eme }}$ lactations conformément au protocole de contrôle laitier qualitatif partiel pratiqué pour cette espèce en France.

Quelles que soient l'espèce et la race, le taux de primipares est supérieur aux données rapportées par le contrôle laitier sur la campagne $2010:+2$ à 5,5 points en bovins et caprins (Institut de l'Élevage et FCEL 2011). Cependant, la hiérarchie entre les races est la même. Cette différence est due à la sélection des élevages collectés. Chez les ovins, les taux de primipares obtenus ici sont supérieurs aux résultats du contrôle de performances qui rapporte $26,7 \%$ de résultats en première lactation en race Lacaune et 22,5\% en race Manech (Institut de l'Élevage et al 2013).

\section{2 / Les systèmes d'alimentation des troupeaux}

Les enquêtes réalisées ont permis une description précise des fourrages conservés (nature, stade de récolte, mode de conservation), pâturages (nature, stade de pâturage) et matières premières (distribuées en l'état ou incluses dans des aliments composés) mis à disposition des animaux. Les apports nutritionnels théoriques ont été calculés grâce aux tables INRA 2007 et INRA-AFZ 2004. Face à la diversité des aliments et afin de faciliter l'étude des facteurs alimentaires, une typologie des régimes a été réalisée pour chaque espèce. Ces typologies, basées sur la part de chaque aliment dans la ration, ont été obtenues avec le logiciel Spad ${ }^{\circledR}$ v7.3 par analyse en composantes principales et classification ascendante hiérarchique.

\section{a) Systèmes d'alimentation dans les élevages bovins}

La typologie a été réalisée à partir de 5580 enquêtes et discrimine 15 régimes (figure 5) : 11 à base de fourrages conservés et 4 basés sur le pâturage. Parmi les régimes à base de fourrages conservés, 3 régimes, majoritaires dans le Nord -Pas-de-Calais et en Bourgogne, se distinguent par l'utilisation de l'Ensilage de Maïs (EM) comme seul fourrage

Figure 5. Composition moyenne des quinze régimes alimentaires des bovins.

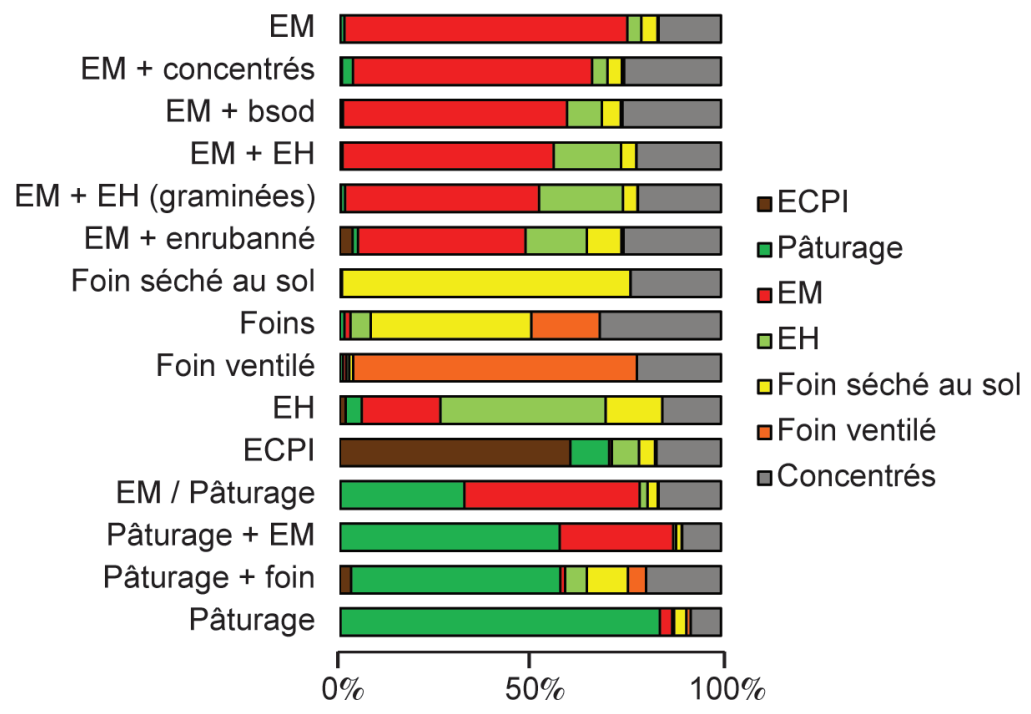

bsod : Bicarbonate de Sodium ; ECPI : Ensilage de Céréales et/ou Protéagineux Immatures ; EH : Ensilage d'Herbe ; EM : Ensilage de Maïs (comprend également les ensilages de sorghos) 
Figure 6. Composition moyenne des onze régimes alimentaires des caprins.

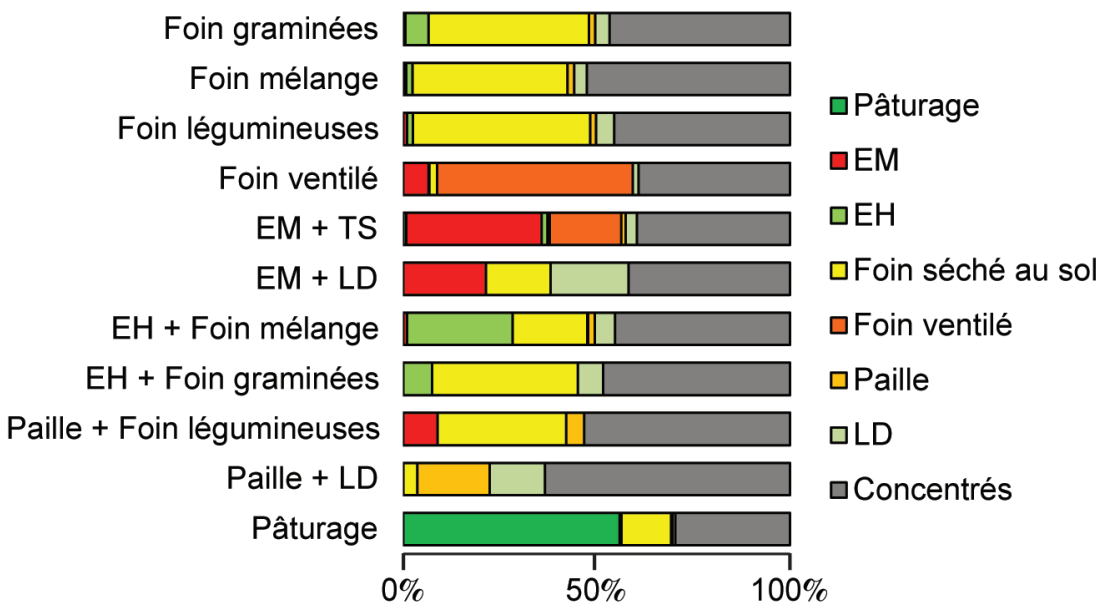

EH : Ensilage d'Herbe ; EM : Ensilage de Maïs ; LD : Luzerne Déshydratée ; Pâturage : comprend aussi l'affouragement en vert ; TS : Tourteau de Soja.

Figure 7. Composition moyenne des treize régimes alimentaires des ovins.

\section{Rayon de Roquefort}

Régimes de bergerie

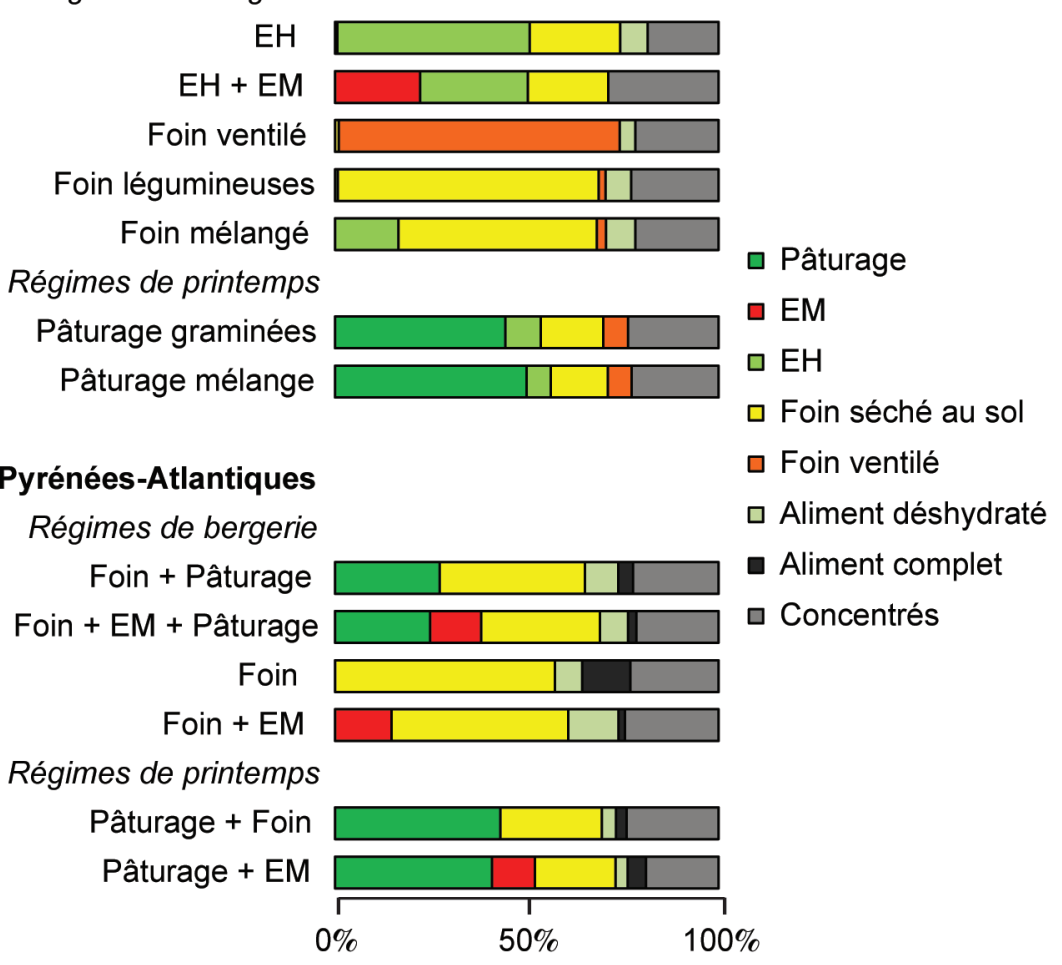

EH : Ensilage d'Herbe ; EM : Ensilage de Maïs

avec une complémentation azotée plus ou moins importante. Dans un de ces régimes, du bicarbonate de sodium est apporté. Trois régimes se caractérisent par l'utilisation de l'EM comme fourrage principal, associé à de l'Ensilage d'Herbe (EH) ou enrubannage, et complémenté en azote et en énergie. Ces régimes sont particulièrement implantés en Alsace et dans les plaines de l'Ouest. Trois régimes à base de foin, séché au sol ou ventilé, très présents en Franche-Comté, comportent une forte complémentation énergétique et de l'Ouest. Un régime contient du foin en complément du pâturage, ainsi qu'une très forte quantité de concentrés. Le dernier régime concerne le pâturage seul, faiblement complémenté en énergie. L'ingestion journalière moyenne des vaches varie de 18,5 à $22,0 \mathrm{~kg}$ de $\mathrm{MS}$ selon les régimes.

b) Systèmes d'alimentation dans les élevages caprins

La typologie a été obtenue à partir de 617 enquêtes. Onze régimes ont été discriminés (figure 6), dont 4 à base de foin. Parmi eux, 3 à base de foin séché au sol sont surtout présents en PoitouCharentes et en région Centre, et 1 à base de foin ventilé est surtout présent en Aveyron. Ces régimes sont souvent fortement complémentés (jusqu'à 50\% de concentrés, notamment du maïs grain) et supplémentés en MG. Deux régimes, très présents en Vendée et dans l'Aveyron, sont à base d'EM, complémenté soit par du tourteau de soja, soit par de la luzerne déshydratée et des tourteaux de colza et tournesol. L'EH est peu présent et souvent associé à du foin dans 2 régimes. Deux rations, qualifiées de « rations sèches à concentrés du commerce » comportent de la paille, du foin et de la luzerne déshydratée en quantités variables. Le pâturage est peu courant, souvent supplémenté en $\mathrm{MG}$, et moins complémenté que les autres régimes (autour de 25\% de concentrés). L'ingestion journalière moyenne est de $2,9 \mathrm{~kg}$ de MS et est peu variable entre régimes (2,8 à 3,2 kg de $\mathrm{MS})$.

c) Systèmes d'alimentation dans les élevages ovins

Les deux bassins de production, utilisant des races différentes et ayant des terroirs et des techniques de production peu semblables, ont été traités séparément (figure 7).

Dans le Rayon, 450 enquêtes ont été utilisées pour réaliser la typologie qui discrimine 7 rations : 5 régimes de bergerie et 2 régimes de printemps. Parmi les régimes de bergerie, 2 sont à base d'EH complémenté par du foin ou de l'EM et 3 sont basés sur du foin, ventilé ou non. Les régimes de printemps contiennent environ $40 \%$ de pâturage (de graminées pures ou multiespèces) complémenté par du foin et des concentrés. L'ingestion journalière moyenne est de $2,9 \mathrm{~kg}$ de MS et diminue en période de pâturage en regard notamment de la baisse de la PL. La part de concentrés varie de 20 à $30 \%$ selon les régimes.

Dans les P-A, la typologie est basée sur 277 enquêtes et aboutit à 6 régimes dont 4 hivernaux et 2 estivaux. Le pâturage hivernal est présent dans 2 régimes, représentant $70 \%$ des enquêtes d'hiver, à raison de 25 à $30 \%$ de la ration. Les 2 
autres régimes hivernaux sont à base de foin associé ou non à de l'EM qui, quand il est utilisé, représente alors de 10 à $15 \%$ de la ration. Les 2 rations printanières sont à base de pâturage $(40 \%$ de la ration) complémenté par de l'EM et/ou $\mathrm{du}$ foin. Les brebis ingèrent en moyenne $2,5 \mathrm{~kg}$ de MS par jour dont environ 20 à $25 \%$ de concentrés avec une diminution logique de la part de concentré entre période hivernale et printanière.

\section{3 / Performances laitières}

La PL, les taux et la composition du lait en $\mathrm{AG}$ et protéines sont présentés par espèce et par race dans le tableau 2.

a) Production laitière et composition du lait

Les vache Holsteins produisent la plus grande quantité de lait $(26,8 \mathrm{~kg} /$ jour $)$ mais avec le plus faible TP $(32,8 \mathrm{~g} / \mathrm{kg})$.
Les Normandes ont la plus faible PL $(20,1 \mathrm{~kg} /$ jour$)$ et les TB et TP les plus élevés (respectivement $43,6 \mathrm{~g} / \mathrm{kg}$ et $35,4 \mathrm{~g} / \mathrm{kg}$ ). Les Montbéliardes sont intermédiaires entre les deux races précédentes.

La PL est très proche entre les deux races caprines : environ $3,9 \mathrm{~kg} / \mathrm{jour}$. Cependant, par rapport aux Saanens, les Alpines produisent un lait plus riche en

Tableau 2. Production laitière et composition du lait moyennes par espèce et par race.

\begin{tabular}{|c|c|c|c|c|c|c|c|}
\hline \multirow[b]{2}{*}{ Caractère } & \multicolumn{3}{|c|}{ Bovins } & \multicolumn{2}{|c|}{ Caprins } & \multicolumn{2}{|c|}{ Ovins } \\
\hline & Montbéliarde & Normande & Holstein & Alpine & Saanen & Lacaune & $\begin{array}{c}\text { Manech Tête } \\
\text { Rousse }\end{array}$ \\
\hline $\mathrm{PL}^{1,{ }^{*}}$ & $24,4 \pm 6,9$ & $20,1 \pm 6,4$ & $26,8 \pm 8,1$ & $3,88 \pm 1,4$ & $3,86 \pm 1,5$ & $1,73 \pm 0,7$ & $1,35 \pm 0,6$ \\
\hline $\mathrm{TB}^{2,{ }^{*}}$ & $39,3 \pm 5,5$ & $43,6 \pm 6,6$ & $39,7 \pm 6,8$ & $38,1 \pm 7,3$ & $35,6 \pm 7,3$ & $75,0 \pm 12,1$ & $69,9 \pm 12,1$ \\
\hline $\mathrm{TP}^{2,{ }^{*}}$ & $33,4 \pm 3,2$ & $35,4 \pm 3,5$ & $32,8 \pm 3,8$ & $33,0 \pm 3,5$ & $31,8 \pm 3,3$ & $55,7 \pm 6,9$ & $51,6 \pm 5,3$ \\
\hline Urée $e^{3,{ }^{*}}$ & $282 \pm 89,5$ & $241 \pm 88,8$ & $206 \pm 113$ & ND & ND & ND & ND \\
\hline Lactose $^{4, *}$ & $48,5 \pm 2,8$ & $47,9 \pm 2,8$ & $48,7 \pm 2,8$ & $46,1 \pm 3,4$ & $46,5 \pm 3,4$ & ND & ND \\
\hline Cellules $\left(10^{3}\right)^{*}$ & $231 \pm 606$ & $320 \pm 770$ & $288 \pm 730$ & $1628 \pm 2150$ & $1648 \pm 1985$ & $313 \pm 1182$ & $433 \pm 1322$ \\
\hline$A G S^{5, * *}$ & $67,1 \pm 5,3$ & $69,0 \pm 5,1$ & $67,9 \pm 5,2$ & $73,5 \pm 3,6$ & $73,4 \pm 3,2$ & $74,2 \pm 4,1$ & $73,0 \pm 3,8$ \\
\hline C4: $0^{5,{ }^{* *}}$ & $3,73 \pm 0,5$ & $3,77 \pm 0,4$ & $3,68 \pm 0,5$ & $2,83 \pm 0,4$ & $2,86 \pm 0,4$ & $3,08 \pm 0,4$ & $3,03 \pm 0,5$ \\
\hline $\mathrm{C} 6: 0^{5,{ }^{, *}}$ & $2,11 \pm 0,3$ & $2,15 \pm 0,2$ & $2,08 \pm 0,3$ & $2,62 \pm 0,3$ & $2,57 \pm 0,3$ & $2,72 \pm 0,4$ & $2,58 \pm 0,4$ \\
\hline $\mathrm{C} 8: 0^{5,{ }^{* *}}$ & $1,30 \pm 0,2$ & $1,34 \pm 0,2$ & $1,29 \pm 0,2$ & $2,80 \pm 0,4$ & $2,66 \pm 0,43$ & $2,09 \pm 0,5$ & $2,02 \pm 0,4$ \\
\hline C10: $0^{5, * *}$ & $2,67 \pm 0,6$ & $2,78 \pm 0,6$ & $2,63 \pm 0,6$ & $10,12 \pm 1,8$ & $9,50 \pm 1,7$ & $8,38 \pm 1,7$ & $7,26 \pm 1,7$ \\
\hline C12:0 $0^{5, * *}$ & $3,09 \pm 0,8$ & $3,20 \pm 0,8$ & $3,09 \pm 0,8$ & $4,16 \pm 1,1$ & $3,90 \pm 1,0$ & $6,26 \pm 1,2$ & $5,28 \pm 1,2$ \\
\hline C14:0 ${ }^{5,{ }^{* *}}$ & $11,8 \pm 1,7$ & $11,8 \pm 1,7$ & $11,8 \pm 1,5$ & $11,1 \pm 1,6$ & $11,0 \pm 1,5$ & $15,3 \pm 1,8$ & $14,6 \pm 1,6$ \\
\hline C16:0 $0^{5, * *}$ & $28,0 \pm 4,7$ & $28,0 \pm 4,6$ & $28,1 \pm 5,2$ & $27,1 \pm 3,3$ & $27,2 \pm 3,3$ & $24,9 \pm 3,0$ & $26,0 \pm 2,7$ \\
\hline$A G M 1^{5, * *}$ & $28,9 \pm 4,7$ & $27,3 \pm 4,7$ & $28,3 \pm 4,8$ & $21,8 \pm 4,2$ & $22,2 \pm 3,9$ & $19,3 \pm 3,7$ & $20,0 \pm 3,7$ \\
\hline Total des C18:1 ${ }^{5, * *}$ & $25,5 \pm 4,7$ & $24,1 \pm 4,5$ & $25,0 \pm 4,7$ & $20,7 \pm 3,0$ & $21,1 \pm 2,8$ & $16,7 \pm 3,7$ & $18,0 \pm 3,7$ \\
\hline Total des C18:1 $\mathrm{cis}^{5, * *}$ & $22,6 \pm 4,2$ & $21,1 \pm 4,1$ & $21,9 \pm 4,1$ & $18,1 \pm 3,3$ & $18,7 \pm 3,2$ & $14,5 \pm 3,4$ & $15,2 \pm 3,6$ \\
\hline C18:1c9 $9^{5, * *}$ & $21,6 \pm 4,0$ & $20,6 \pm 4,0$ & $21,3 \pm 4,2$ & $18,0 \pm 3,5$ & $18,6 \pm 3,3$ & $12,8 \pm 3,3$ & $13,5 \pm 3,6$ \\
\hline$A G P I^{5, * *}$ & $4,0 \pm 0,7$ & $3,6 \pm 0,6$ & $3,7 \pm 0,6$ & $4,1 \pm 0,9$ & $4,1 \pm 0,9$ & $4,4 \pm 0,7$ & $3,9 \pm 0,5$ \\
\hline Total des C18:2, & $2,76 \pm 0,6$ & $2,51 \pm 0,5$ & $2,60 \pm 0,5$ & $3,10 \pm 1,1$ & $3,01 \pm 1,0$ & $2,97 \pm 0,6$ & $2,69 \pm 0,5$ \\
\hline Indice d'élongation ${ }^{6, * *}$ & $3,36 \pm 0,5$ & $3,35 \pm 0,5$ & $3,44 \pm 0,5$ & $5,10 \pm 0,9$ & $4,82 \pm 0,9$ & $4,84 \pm 0,9$ & $4,28 \pm 0,9$ \\
\hline Caséines totales $^{6, * *}$ & $83,9 \pm 1,4$ & $83,5 \pm 1,2$ & $82,9 \pm 1,4$ & ND & ND & $79,7 \pm 0,5$ & $81,3 \pm 0,6$ \\
\hline Caséine as $1^{7, * *}$ & $28,0 \pm 0,6$ & $27,8 \pm 0,7$ & $27,9 \pm 0,7$ & ND & ND & $25,4 \pm 0,9$ & $24,7 \pm 0,8$ \\
\hline Caséine as $2^{7, * *}$ & $9,66 \pm 0,3$ & $9,89 \pm 0,3$ & $9,70 \pm 0,4$ & ND & ND & $10,7 \pm 1,7$ & $11,6 \pm 2,4$ \\
\hline Caséine $\beta^{7,,^{* *}}$ & $36,3 \pm 0,9$ & $36,2 \pm 1,2$ & $36,1 \pm 1,2$ & ND & ND & $35,0 \pm 2,5$ & $36,2 \pm 3,0$ \\
\hline Caséine $\mathrm{K}^{7, * *}$ & $9,97 \pm 0,6$ & $9,87 \pm 0,5$ & $9,44 \pm 0,6$ & ND & ND & $8,6 \pm 0,5$ & $8,8 \pm 1,2$ \\
\hline $\begin{array}{l}\text { Somme } \alpha \text {-lactalbumine } \\
+\beta \text {-lactoglobuline }{ }^{6, *}\end{array}$ & $12,4 \pm 1,2$ & $11,9 \pm 1,2$ & $12,5 \pm 1,4$ & ND & ND & $12,5 \pm 0,5$ & $12,9 \pm 0,6$ \\
\hline
\end{tabular}

${ }^{1} \mathrm{PL}$ (Production Laitière) en kg/jour (bovins, caprins) et L/jour (ovins) ; ${ }^{2} \mathrm{~TB}$ (Taux Butyreux) et TP (Taux Protéique) en g/kg (bovins, caprins) et $\mathrm{g} / \mathrm{L}$ (ovins) $;{ }^{3}$ Urée en $\mathrm{mg} / \mathrm{L} ;{ }^{4}$ Lactose en $\mathrm{g} / \mathrm{kg} ;{ }^{5}$ Acides gras en $\%$ des AGT ;

${ }^{6}$ Indice d'élongation $=(C 8: 0+C 10: 0+C 12: 0+C 14: 0) /(C 4: 0+C 6: 0) ;{ }^{7}$ Protéines en $\%$ de la MP totale.

"Données du contrôle laitier officiel ; ${ }^{* *}$ Données estimées par MIR via les équations PhénoFinlait.

ND : Non Disponible. 
MG (TB de $38,1 \mathrm{~g} / \mathrm{kg}$ vs $35,6 \mathrm{~g} / \mathrm{kg}$ ) et en MP (TP de 33,0 g/kg vs 31,8 g/kg).

Pour les bovins et les caprins, ces performances sont supérieures aux résultats du contrôle laitier sur la campagne (Institut de l'Élevage et FCEL 2011a et b), mais semblent représentatives de la situation nationale de chaque race. Les différences s'expliquent par le fait qu'il s'agit de résultats ponctuels et non de lactations entières.

Pour les ovins, la production moyenne journalière est de 1,73 L en race Lacaune et 1,35 L en race Manech. Ces chiffres sont cohérents avec la moyenne des élevages au contrôle laitier. La plus grande richesse du lait des Lacaunes par rapport au lait des Manechs, tant en $\mathrm{MG}$ (75,0 g/L vs 69,9 g/L) qu'en MP (55,7 g/L vs $51,6 \mathrm{~g} / \mathrm{L}$ ) est principalement due à l'antériorité de la sélection sur la richesse du lait, qui a débutée dans les années 1980 en race Lacaune et seulement dans les années 2000 en race Manech.

\section{b) Profil moyen du lait en acides gras}

La MG du lait de vache est composée de 67 à $69 \%$ d'AGS, de 27 à $29 \%$ d'AGMI et de 3,6 à 4\% d'AGPI. Ce profil est cohérent au regard des plages de variations obtenues pour différents régimes alimentaires français et énoncées dans la bibliographie : Chilliard et al (2007) indiquent des moyennes de 69\% d'AGS, $25 \%$ d'AGMI et $4 \%$ d'AGPI. Peyraud et al (2011) rapportent des valeurs de 65,9 à 73,8\% d'AGS, 23,1 à $29,4 \%$ d'AGMI, et 3 à 4,4\% d'AGPI. Les Normandes produisent un peu plus d'AGS et les Montbéliardes produisent davantage d'AGPI. Parmi ces AG, l'acide palmitique C16:0 est le plus présent : $28 \%$ des AGT quelle que soit la race. L'acide oléique $\mathrm{C} 18: 1 \mathrm{c} 9$ est également très présent (20 à $22 \%$ des AGT). La teneur en acide myristique C14:0 s'élève à $11,8 \%$ des AGT dans chacune des races. Les parts relatives des AG individuels sont conformes à celles rapportées dans la bibliographie (Couvreur et al 2006).

En caprin, la MG est composée de $73,5 \%$ d'AGS, 22\% d'AGMI et 4\% d'AGPI quelle que soit la race. Comme en bovins, le C16:0 est l'AG le plus présent (27\% des AGT), mais la part des AG courts est plus importante, en particulier la part relative d'acide caprique (C10:0, autour de 10\% des AGT) responsable du goût particulier des produits à base de lait de chèvre. Les teneurs en $\mathrm{C} 14: 0$ et $\mathrm{C} 18: 1 \mathrm{c} 9$ s'élèvent respectivement à 11 et $18 \%$ des AGT. Les profils observés dans la bibliographie sont hétérogènes selon les auteurs. La teneur en AGS varie entre 70 et $72 \%$ des AGT, celle en AGMI de 19,5 à $26 \%$ des AGT et les AGPI sont présents à hauteur de
4 à 5,5\% en moyenne selon les données de Ceballos et al (2009) et de Andueza et al (2013). Les teneurs en C10:0, $\mathrm{C} 14: 0, \mathrm{C} 16: 0$ et $\mathrm{C} 18: 1 c 9$ varient respectivement de 9,7 à $11,2 \%, 9,8$ à $12,5 \%$, 24 à $30,5 \%$ et 12 à $17 \%$ des AGT selon les études (Doyon 2005, Chilliard et al 2006, Ceballos et al 2009, Andueza et al 2013). Enfin, l'ANSES énonce en 2011 un profil moyen en $A G$ du lait caprin contenant 74,6\% d'AGS, 29,7\% de C16:0, 11,1\% de C10:0 et de C14:0 et $18,9 \%$ de $\mathrm{C} 18: 1 \mathrm{c} 9$. Les résultats obtenus ici sont donc conformes aux résultats récents de la littérature.

La MG des laits de brebis est composée de 73 à $74 \%$ d'AGS, de 19 à 20\% d'AGMI et de 3,9 à $4,4 \%$ d'AGPI. Comme dans les autres espèces laitières, le C16:0 est le plus représenté ( 25 à $26 \%$ selon la race). Les AG courts sont plus présents chez les brebis que chez les vaches. Par rapport à la race Lacaune, les brebis Manechs présentent un lait plus riche en $\mathrm{C} 16: 0$ et moins riche en C14:0. La teneur en C18:1c9 est moins élevée qu'en bovins et caprins. Les profils rapportés dans la bibliographie sont hétérogènes et très peu renseignés en ce qui concerne les races et les systèmes de production français. Les teneurs en AGS obtenues sont plus élevées (+ 3 à 4 points) que celles rapportées dans la littérature (Carta 2008, Lagriffoul 2008, De La Fuente et al 2009, Raynal-Ljutovac et al 2010). Les principales différences concernent le C16:0 mais surtout le C14:0. Le type de lait analysé dans le cadre de PhénoFinlait peut être à l'origine de cette différence : lait de brebis jeunes, à la traite du matin et avec une grande partie des mesures réalisées en période de bergerie. A l'inverse, les études mentionnées concernent du lait de mélange représentatif de l'ensemble de la campagne.

\section{c) Profil moyen du lait en protéines}

Les caséines représentent environ $83 \%$ de la MP du lait de vache, conformément à la littérature ( 81 à $82 \%$ d'après Coulon et al 1998), avec peu de différences entre races. Parmi les caséines, la caséine $\beta$ est la plus présente (43 à $44 \%$ des caséines totales et $36 \%$ de la MP totale), devant les caséines $\alpha$ s 1 (33 à 34\% des caséines totales), as 2 et $\kappa$ (11 à $12 \%$ des caséines totales chacune). Ces résultats sont en accord avec les ordres de grandeur énoncés dans la littérature (Grosclaude 1988, Tremblay et al 2003), malgré de faibles différences qui peuvent provenir de la réaffectation de la protéolyse dans notre étude, notamment pour ce qui concerne la caséine $\beta$.

La part des caséines représente $80 \%$ de la MP totale en ovins. La teneur en caséines est légèrement plus importante en race Manech qu'en race Lacaune.
Au sein des caséines, et conformément aux données bovines, la caséine la plus représentée est la caséine $\beta$ (35 à $36 \%$ de la MP totale) devant les caséines $\alpha$ s 1 (25\% de la MP totale), $\alpha$ s2 (11\% de la MP totale) et $\kappa(8,6$ à $8,8 \%$ de la MP totale). La caséine $\alpha$ s 2 est un peu plus présente dans les laits ovins que dans les laits bovins, au détriment de la caséine $\kappa$. Les deux principales protéines solubles représentent entre 12 et $13 \%$ de la MP totale. Ces résultats sont en accord avec ceux de la littérature, relativement peu fournie. Pellegrini et al (1994) rapportaient un taux de caséines de $82 \%$ en race Lacaune pour un TP moyen de 53,5 g/L. Ici, le taux de caséines apparaît plus faible $(79,7 \%)$ mais le TP moyen est supérieur $(55,7 \mathrm{~g} / \mathrm{L})$. Là encore, les différences peuvent venir de la spécificité du protocole de collecte.

\section{Conclusion}

PhénoFinlait est le premier programme français à s'intéresser au phénotypage en routine de la composition fine du lait. Grâce à l'implication de nombreux acteurs, un phénotypage et un génotypage de grande ampleur ont pu être réalisés dans plus de 1500 élevages bovins, caprins et ovins représentatifs de la diversité des situations d'élevage françaises. Une base de données regroupant 862754 analyses laitières, 12604 génotypages, et 8508 enquêtes d'alimentation a été constituée. Cette collecte de grande ampleur est originale en France, comme à l'international. Un pilotage efficace ainsi que la formation des différents acteurs ont permis ce travail. Acteurs de terrain (ECEL, ES, entreprises de mise en place de semence, laboratoires d'analyse) et de la recherche et développement (Institut de l'Élevage, INRA, Actalia Cecalait) ont uni leurs efforts afin de servir les intérêts de la profession : le CNIEL, le Comité National Brebis Laitières et France Génétique Élevage.

PhénoFinlait a permis d'actualiser les références existantes sur la composition du lait et la conduite (notamment alimentaire) des troupeaux laitiers. Ces descriptions, déclinées à l'échelle raciale et à l'échelle d'un bassin de production sont particulièrement intéressantes, la majorité des références existantes ayant été obtenues en situation expérimentale. PhénoFinlait offre un état des lieux des situations d'élevage français rencontrées dans les fermes commerciales et permet de compléter la littérature qui fournit parfois peu de données concernant les pratiques d'alimentation et la composition fine du lait pour les trois espèces laitières.

Les apports de PhénoFinlait concernant le phénotypage de la composition fine du lait sont importants. D'une part, 
la meilleure connaissance de la technologie MIR, utilisée en routine dans les laboratoires, est un atout pour les acteurs du conseil en élevage. PhénoFinlait a permis de mettre en évidence les précautions à prendre pour pouvoir utiliser cette technologie. L'impact de la congélation et de l'utilisation de conservateur sur le spectre MIR a notamment été étudié. La nécessité de standardiser les spectres ou d'ajuster périodiquement les estimations obtenues grâce aux équations afin d'assurer des résultats stables au cours du temps et entre analyseurs a été mise en évidence.

D'autre part, PhénoFinlait a permis de développer de nombreuses équations pour quantifier les composants fins présents dans le lait. Les équations d'estimation des teneurs en AG des laits de bovins sont de qualité équivalente à celles développées par ailleurs (Soyeurt et al 2012, De Marchi et al 2014). Les équations présentant de très bonnes performances $\left(\mathrm{R}^{2}\right.$ supérieur à 0,91$)$ peuvent être utilisées en routine. Les équations dont le $\mathrm{R}^{2}$ est supérieur à 0,75 peuvent être utilisées en amélioration génétique ou pour le pilotage du troupeau surtout si plusieurs mesures sont réalisées sur le même animal au cours du temps (MauriceVan Eijnhoven et al 2013). Néanmoins, l'application de ces équations à des laits d'animaux de races locales ou recevant une alimentation atypique nécessiterait une validation préalable si les profils s'avéraient assez différents de ceux utilisés pour l'étalonnage du modèle.

Pour les caprins et les ovins PhénoFinlait est le premier programme à proposer un phénotypage de la composition fine du lait. Enfin, PhénoFinlait est le premier programme à quantifier les protéines à partir d'un spectre de masse, permettant ensuite un phénotypage fiable via l'analyse des spectres MIR.

\section{Remerciements}

Le programme PhénoFinlait est cofinancé par l'ANR, Apis-gène, France Génétique Elevage, FranceAgriMer, Ministère en charge de l'Agriculture dont le compte d'affectation spéciale CASDAR, fond IBiSA et Union Européenne. Les auteurs remercient les partenaires du consortium PhénoFinlait, les acteurs de terrain et les éleveurs ainsi que les stations expérimentales de l'INRA pour leur contribution au développement des équations. Un merci particulier à F. Barillet, L. Bianchi, C. Dos, M. Douguet, S. Esvan, F. Faucon-Lahalle, S. Guisnel, B. Huquet, L. Journaux, C. Lecomte, S. Leverrier, E. Poulain et G. Thomas. Ce travail a été conduit dans le cadre des programmes de trois Unités Mixtes Technologiques : GENEpR, 3G et RIEL.

\section{Références}

Andueza D., Rouel J., Chilliard Y., Leroux C., Ferlay A., 2013. Prediction of the goat milk fatty acids near infrared reflectance spectroscopy. Eur. J. Lipid. Sci. Technol., 115, 612-620.

AOAC, 2000. Official Methods for Analysis. $17^{\text {th }}$ ed. AOAC International Gaithersburg, MD.

Bastin C., Soyeurt H., Gengler N., 2013. Genetic parameters of milk production traits and fatty acid contents in milk for Holstein cows in parity 1-3. J. Anim. Breed. Genet., 130, 118-127.

Bisgard Oldrup D., van den Bijgaart H., Leray O., Ferrand M., Müller B., 2010. New applications of mid infra-red spectrometry for the analysis of milk and milk products: saturated and unsaturated fatty acids. Bul. Int. Dairy Fed., $447,23 p$.

Boichard D., Govignon-Gion A., Larroque H., Maroteau C., Palhière I., Tosser-Klopp G., Rupp R., Sanchez M.P., Brochard M., 2014. Déterminisme génétique de la composition en acides gras et protéines du lait des ruminants. In : PhénoFinlait: Phénotypage et génotypage pour la compréhension et la maîtrise de la composition fine du lait. Brochard M., Boichard D., Brunschwig P., Peyraud J.L. (Eds). Dossier, INRA Prod. Anim., 27, 283-298.

Bonfatti V., Di Martino G., Carnier P., 2011. Effectiveness of mid-infrared spectroscopy for the prediction of detailed protein composition and contents of protein variants of individual milk of Simmental cows. J. Dairy Sci., 94, 5776-5785.

Carta A., Casu S., Usai M.G., Addis M., Fiori M., Fragh A., Miari S., Mura L., Piredda G., Schibler L., 2008. Investigating the genetic component of fatty acid content in sheep milk. Small Rum. Res., 79, 22-28.

Ceballos L.S., Morales E.R., de la Torre Adarve G., Castro J.D., Martínez L.P., Sampelayo M.R.S., 2009. Composition of goat and cow milk produced under similar conditions and analyzed by identical methodology. J. Food Comp. Anal., 22, 322-329.

Cecchinato A., De Marchi M., Gallo L. Bittante G., Carnier P., 2009. Mid-infrared spectroscopy predictions as indicator traits in breeding programs for enhanced coagulation properties of milk. J. Dairy Sci., 92, 5304-5313.

Chilliard Y., Ferlay A., Mansbridge R.M., Doreau M., 2000. Ruminant milk fat plasticity: nutritional control of saturated, polyunsaturated, trans and conjugated fatty acids. Ann. Zootech., $49,181-205$.

Chilliard Y., Rouel J., Leroux C., 2006. Goat's alpha s1 casein genotype influences its milk fatty acid composition and delta-9 desaturation ratios. Anim. Feed. Sci. Technol., 131, 474-487.

Chilliard Y., Glasser F., Enjalbert F., Ferlay A., Bocquier F., Schmidely P., 2007. Données récentes sur les effets de l'alimentation sur la composition en acides gras du lait de vache, de chèvre et de brebis. Renc. Rech. Rum., 14, 321-328.

Confédération Générale de Roquefort, 2012. Rapport annuel.

Coppa M., Ferlay A., Leroux C., Jestin M., Chilliard Y., Martin B., Andueza D., 2010. Prediction of milk fatty acid composition by near infrared reflectance spectroscopy. Int. Dairy J., 20,182-189.

Coulon J.B., Hurtaud C., Rémond B., Vérité R., 1998. Facteurs de variation de la proportion de caséines dans les protéines du lait de vache. INRA Prod. Anim., 11, 299-310.

Couvreur S., Hurtaud C., Lopez C., Delaby L., Peyraud J.L., 2006. The linear relationship between the proportion of fresh grass in the cow diet, milk fatty acid composition and butter properties. J. Dairy Sci., 89, 1956-1969.

De la Fuente L.F., Barbosa E., Carriedo J.A., Gonzalo C., Arenas R., Fresno J.M., San
Primitivo F., 2009. Factors influencing variation of fatty acid content in ovine milk. J. Dairy Sci., 92, 3791-2151.

De Marchi M., Penasa M., Cecchinato A., Mele M., Secchiari P., Bittante G., 2011. Effectiveness of mid-infrared spectroscopy to predict fatty acid composition of Brown Swiss bovine milk. Animal, 5, 1653-1658.

De Marchi M., Toffanin V., Cassandro M. Penasa M., 2014. Invited review: Mid-infrared spectroscopy as phenotyping tool for milk traits. J. Dairy Sci., 97, 1171-1186.

Doyon A., 2005. Influence de l'alimentation sur la composition du lait de chèvre : revue des travaux récents. In : Colloque sur la chèvre. L'innovation : un outil de croissance. CRAAQ, Saint-Hyacinthe, Québec, 24p.

Ferrand-Calmels M., Palhière I., Brochard M., Leray O., Astruc J.M., Aurel M.R., Barbey S., Bouvier F., Brunschwig P., Caillat H., Douguet M., Faucon-Lahalle F., Gelé M., Thomas G., Trommenschlager J. M., Larroque H., 2014 Prediction of fatty acid profiles in cow, ewe, and goat milk by mid-infrared spectrometry. J. Dairy Sci., 97, 17-35.

Grosclaude F., 1988. Le polymorphisme génétique des principales lactoprotéines bovines. Relations avec la quantité, la composition et les aptitudes fromagères du lait. INRA Prod. Anim., 1, 5-17.

IDF, 2000. Standard 141C: Whole milk Determination of milkfat, protein and lactose content - Guidance on the operation of midinfrared instruments. Int. Dairy Fed., Brussels, Belgium.

INRA, 2007. Alimentation des bovins, ovins et caprins. Besoins des animaux. Valeurs des aliments. Tables INRA 2007. Editions Quae, Paris, France, 307p.

INRA-AFZ, 2004. Tables de composition et de valeur nutritive des matières premières destinées 
aux animaux d'élevage : porcs, volailles, bovins, ovins, caprins, lapins, chevaux, poissons. D. Sauvant, J.-M. Perez, G. Tran (eds), $2^{\text {e }}$ édition révisée, INRA, Paris, 301p.

Institut de l'Élevage, FCEL, 2011a. Résultats de contrôle laitier - espèce bovine - 2010. Ed. Institut de l'Élevage, Coll. Résultats, 105p.

Institut de l'Élevage, FCEL, 2011b. Résultats de contrôle laitier - espèce caprine - 2010. Ed. Institut de 1'Élevage, Coll. Résultats, 16p.

Institut de l'Élevage, FCEL, CNBL, 2013. Résultats de contrôle laitier - France 2012. Ed. Institut de l'Élevage, Coll. Résultats, 153p.

Interprofession Lait de Brebis des PyrénéesAtlantiques, 2012. Rapport annuel.

ISO-IDF, 2001. Milk and milk products Extraction methods for lipids and liposoluble compounds International Standard ISO 14156IDF 172:2001. Int. Dairy Fed., Brussels, Belgium.

ISO-IDF, 2002. Milk fat - Preparation of fatty acid methyl esters International Standard ISO 15884-IDF 182:2002. Int. Dairy Fed., Brussels, Belgium.

ISO-IDF, 2002. Milk fat - Determination of the fatty acid composition by gas-liquid chromatography. ISO 15885-IDF 184. Int. Dairy Fed., Brussels, Belgium.

ISO-IDF, 2009. Milk - Definition and evaluation of the overall accuracy of alternative methods of milk analysis - Part 2: Calibration and quality control in the dairy laboratory. International Standard ISO 8196-2-IDF 128-2:2009. Int. Dairy Fed., Brussels, Belgium.

Kramer J.K.G., Fellner V., Dugan M.E.R., Sauer F.D., Mossoba1 M.M., Yurawecz M.P., 1997. Evaluating acid and base catalysts in the methylation of milk and rumen fatty acids with special emphasis on conjugated dienes and total trans fatty acids. Lipids, 32, 1219-1228.

Lagriffoul G., 2008. Composition fine du lait et des fromages de brebis. Document de synthèse du programme mené dans le cadre du Comité
Lait de Brebis de l'Office de l'Elevage, Réf. Institut de l'Elevage 150857010,6p.

Leray O., Ferrand M., Larroque H., Astruc J M., Douguet M., Brochard M., Duhem K., 2011. Harmonisation of milk analysers for fatty acid determination by FTMIR - An essential step prior to collective data use. Congrès ICAR, Bourg-en-Bresse, France.

Maurice-Van Eijndhoven M.H.T., Soyeurt H., Dehareng F., Calus M.P.L., 2013. Validation of fatty acid predictions in milk using mid-infrared spectrometry across cattle breeds. Animal, 7, 348-354.

Miranda G., Boumahrou N., Bianchi L., Pinard A., Saadaoui B., Guillot A., Henry C., Bevilacqua C., Beauvallet C., Bellier S., Cebo C., Martin P., 2011. Understanding milk protein complexity to produce accurate phenotypes. In: $8^{\text {th }}$ Int. Milk Genomics Consortium Symp., Melbourne, Australia.

Pellegrini O., Remeuf F., Rivemale M., 1994 Evolution of physicochemical characteristics and renneting properties of ewe's milk collected in "Roquefort area". Lait 74, 425-442.

Peyraud J.L., Rouillé B., Hurtaud C., Brunschwig P., 2011. Les acides gras du lait de vache : composition et maîtrise par l'alimentation. Ed. Institut de l'Élevage - UMT Riel INRA - Cniel, Coll. Synthèse, 36p.

Raynal-Ljutovac K., Lagriffoul G., 2010. Matière grasse du lait. Cas particulier des laits de chèvre et de brebis. Sciences des aliments, 29, 89-104.

Rutten M.J.M., Bovenhuis H., Hettinga K.A., van Valenberg H.J., van Arendonk J.A., 2009. Predicting bovine milk fat composition using infrared spectroscopy based on milk samples collected in winter and summer. J. Dairy Sci., 92, 6202-6209.

Rutten M.J.M., Bovenhuis H., Heck J.M.L., van Arendonk J.A.M., 2011. Predicting bovine milk protein composition based on Fourier transform infrared spectra. J. Dairy Sci., 94, 5683-5690.
Soyeurt H., Dardenne P., Dehareng F., Lognay G., Veselko G., Marlier M., Bertozzi C., Mayeres P., Gengler N., 2006. Estimating fatty acid content in cow milk using mid-infrared spectrometry. J. Dairy Sci., 89, 3690-3695.

Soyeurt H., Dehareng F., Gengler N., McParland S., Wall E., Berry D. P., Coffey M., Dardenne P., 2011. Mid-infrared prediction of bovine milk fatty acids across multiple breeds, production systems, and countries. J. Dairy Sci., 94, 1657-1667.

Soyeurt H., McParland S., Berry D., Wall E., Coffey M., Gengler N., Dehareng F., Dardenne P., 2012. Mid-infrared predictions of fatty acids in bovine milk: Final results of the RobustMilk project. Proc. $63^{\text {rd }}$ Annual Meeting EAAP 2012 , Bratislava, Slovakia.

Stoop W.M., van Arendonk J.A.M., Heck J.M.L, van Valenberg H.J.F., Bovenhuis H., 2008. Genetic Parameters for Major Milk Fatty Acids and Milk Production Traits of Dutch Holstein-Friesians. J. Dairy Sci., 91, 385-394.

Tenenhaus M., 2002. La Regression PLS : Théorie et Pratique. Technip, Lassay-lesChâteaux, France.

Tremblay L., Laporte M.F., Leonil J., Dupont D., Paquin P., 2003. Quantitation of proteins in milk and milk products. In: Advanced Dairy Chemistry: Volume 1: Proteins, Part A, Fox, P.F. and McSweeney, P.L.H., 49-138.

Valenti B., Martin B., Andueza D., Leroux C., Labonne C., Lahalle F., Larroque F., Brunschwig P., Lecomte C., Brochard M., Ferlay A., 2013. Infrared spectroscopic methods for the discrimination of cows' milk according to the feeding system, cow breed and altitude of the dairy farm. Int. Dairy J., 32, 26-32.

Visker M., Heck J., Koks P., Leon-Kloosterziel K., Meuldijk R., Schennink A., Schopen G., Stoop M., van Arendonk J., 2006. The Dutch Milk Initiative: genetic improvement of milk quality traits and product innovation. $3^{\text {rd }}$ Int. Symp. Milk Genomics and Human Health, Brussels, Belgium.

\section{Résumé}

Les acteurs des filières laitières bovine, caprine et ovine françaises se sont regroupés dans le programme PhénoFinlait autour d'un but commun : caractériser la composition du lait en Acides Gras (AG) et protéines afin de la maîtriser. La quantification des AG et des protéines devait être possible à grande échelle et à moindre coût avant d'identifier des leviers permettant d'adapter cette composition à la demande. PhénoFinlait s'est organisé autour de trois objectifs : $i$ ) caractériser précisément la composition du lait, ii) phénotyper et génotyper une large population de femelles sur l'ensemble du territoire français et iii) identifier les leviers génétiques et alimentaires permettant de maîtriser cette composition. La spectrométrie dans le Moyen InfraRouge (MIR) a été choisie comme méthode de quantification à haut débit des composants du lait. Elle permet la quantification précise en routine de 15 à $27 \mathrm{AG}$, des quatre caséines et des deux protéines majeures du lactosérum. Une collecte de données de grande ampleur a été mise en ouvre dans plus de 1500 élevages bovins, caprins et ovins. Les données de production laitière, les spectres MIR du lait, les informations sur le stade physiologique des femelles et sur la composition de l'alimentation des troupeaux ont été recueillies. Plus de 12000 vaches, chèvres et brebis ont été génotypées. Finalement, plus de 800000 données représentatives des situations de l'élevage français ont été stockées dans une base de données destinée à l'étude du déterminisme génétique de la composition en AG et en protéines du lait, et des facteurs d'élevage l'influençant. 


\begin{abstract}
Large scale phenotyping and genotyping of milk fine composition in the cow, goat and ewe

PhénoFinlait gathers together the actors of dairy industries including cattle, sheep and goats; around a common goal: monitoring milk Fatty Acid (FA) and protein composition. Quantifying FA and proteins by a reliable and cheap large-scale method is necessary before identifying the ways to adapt this composition to consumers' and dairy processors' demand. The objectives of the project were i) to characterize precisely the milk composition, ii) to phenotype and genotype a large population of females all over France, and iii) to identify the genetic and feeding levers to control this composition. Mid infrared (MIR) spectrometry has been chosen to quantify milk FA and proteins. With this method, the four caseins, the two main whey proteins, and 15 to 27 FA can be quantified routinely and precisely. A large-scale data collection has been carried out in more than 1,500 commercial dairy cattle, goat and sheep farms. Dairy production, MIR spectra, female physiological stages, and composition of the diet were collected. More than 12,000 cows, goats and ewes were also genotyped. Finally, more than 800,000 representative data are stored in a database for the study of the genetic determinism of milk FA and protein composition, and the impact of husbandry.
\end{abstract}

GELÉ M., MINERY S., ASTRUC J.-M., BRUNSCHWIG P., FERRAND-CALMELS M., LAGRIFFOUL G., LARROQUE H., LEGARTO J., LERAY O., MARTIN P., MIRANDA G., PALHIERE I., TROSSAT P., BROCHARD M., 2014. Phénotypage et génotypage à grande échelle de la composition fine des laits dans les filières bovine, ovine et caprine. In : PhénoFinlait : Phénotypage et génotypage pour la compréhension et la maîtrise de la composition fine du lait. Brochard M., Boichard D., Brunschwig P., Peyraud J.-L. (Eds). Dossier, INRA Prod. Anim., 27, 255-268. 